\title{
A review of combined advanced oxidation technologies for the removal of organic pollutants from water
}

\author{
Jimoh O. Tijani \& Ojo O. Fatoba \& GodfreyMadzivire and Leslie F. Petrik
}

\begin{abstract}
Water pollution through natural and anthropogenic activities has become a global problem causing short-and long-term impact on human and ecosystems. Substantial quantity of individual or mixtures of organic pollutants enter the surface water via point and nonpoint sources and thus affect the quality of freshwater. These pollutants are known to be toxic and difficult to remove by mere biological treatment. To date, most researches on the removal of organic pollutants from wastewater were based on the exploitation of individual treatment process. This single-treatment technology has inherent challenges and shortcomings with respect to efficiency and economics. Thus, application of two advanced treatment technologies characterized with high efficiency with respect to removal of primary and disinfection byproducts in wastewater is desirable. This review article focuses on the application of integrated technologies such as electrohydraulic discharge with heterogeneous photocatalysts or sonophotocatalysis to remove target pollutants. The information gathered from more than 100 published articles, mostly laboratories studies, shows that process integration effectively remove and degrade recalcitrant toxic contaminants in wastewater better than singletechnology processing. This review recommends an improvement on this technology (integrated electrohydraulic discharge with heterogeneous photocatalysts) viz-a-vis cost reduction in order to make it accessible and available in the rural and semi-urban settlement. Further recommendation includes development of an economic model to establish the cost implications of the combined technology. Proper monitoring, enforcement of the existing environmental regulations, and upgrading of current wastewater treatment plants with additional treatment steps such as photocatalysis and ozonation will greatly assist in the removal of environmental toxicants.
\end{abstract}

\section{Introduction}

The widespread discharge of industrial wastewater effluent; extensive production, consumption, and utilization of chemical products; and growing world population contributes substantially to the increasing accumulation of priority organic pollutants (POPs) in the environment (Capocelli et al. 2012; Jiang et al. 2014). This ugly trend is mostly common in developing countries where environmental regulatory and monitoring framework is not properly enforced; hence, continuous discharge of wastewater off-site affects human health and the entire ecosystem. A wide range of these organic compounds remain unregulated 
or in the process of regulation, poorly understood, and widely detected in natural and engineered environments such as water at low concentration due to partial elimination by combination of well-established conventional wastewater treatment technology (Chefetz et al. 2008; Zhou et al. 2009; Fawell and Ong 2012; Bahmani et al. 2013). These chemical constituents ranging from complex organic dyes, antibiotics, phenols, pesticides, to chlorinated compounds enter the environment via direct or indirect sources such as indiscriminate discharge of residual pesticides, fertilizers, and poor agricultural runoff which affect the water purity status (Bolong et al. 2009). In spite of their low concentration in the environment, they constitute environmental nuisance to the ecosystem owing to their high endocrine-disrupting potential and acute toxicity (Machulek Jr et al. 2013; Swaminathan et al. 2013). Currently, large volume of different chemical composition wastewater is generated via domestic and industrial activities and subsequently discharged into the environment (Oller et al. 2011). These natural and artificial phenomenons contributed to reduction in the volume of freshwater, which is a serious problem that presently threatens human survival. Fresh, uncontaminated water and adequate sanitary measures remain critical to human existence and enhancement of socioeconomic sustainability as the two are now becoming an endangered commodity (Houtman 2010). Thus, lack of fresh clean water and consumption of nonhygienic water led to several epidemic outbreaks especially among children in developing nations. In 2010 alone, more than 4.4 million children below the age of 5 worldwide died of diarrhea and other water-borne diseases (WHO 2012). It is a known fact that the demand for freshwater already surpasses supply and even double the population growth. Han et al. (2009) substantiated further that lack of clean water is biting hard on people as the available clean water is just less than one half of the $1 \%$ of surface water on earth. In spite of apparently giant stride and proactive steps taken by governmental and nongovernmental organizations including setting up legal framework and provision of funding, support, and campaign to protect and improve the quality of water. The water quality deterioration is increasing due to increase discharge of wastewater containing recalcitrant, inhibitory pollutants into the immediate environment (Khan et al. 2009; Chong et al. 2010). Thus, higher concentrations of these pollutants are expected to be aggravated in the nearest future due to the ever-increasing pollution index (Luiz et al. 2010). A study has shown that the variation in the concentration of contaminants detected in water could be ascribed to different consumption pattern across countries (Luiz et al. 2011). This development is not an innovation but rather an ugly inclination that needs to be checked and examined. Thus, with the rising demand for safe drinking water together with the high volume of wastewater, urgent practical and tactical solutions are required. One of the immediate answers required to reduce the pressure put on the limited clean water is the option of wastewater reclamation and recycling of the treated polluted water.

Currently, the available conventional treatment technologies have inherent challenges and shortcomings with respect to applications, design, effectiveness, and economics (Gultekin and Ince 2007; Tsai et al. 2009). Biological treatment, for instance, does not produce satisfactory result especially when treating industrial waste-water. This is due to the presence of biologically recalcitrant, inhibitory, and toxic pollutants that are resistant to biological degradation. Aside from this, other treatment methods such as ozonation, air stripping, coagulation/flocculation, reverse osmosis, ultrafiltration, chlorination, etc. produces toxic disinfection by-products 
(DBP) that are genotoxic, mutagenic, and carcinogenic to human health. Adsorption produces toxic sludge, and, not just that, pollutants are being transformed from one phase to another without necessarily being decomposed (Kasprzyk-Hordern et al. 2009; Maletz et al. 2013). Other treatment processes may be hindered by economics and wastewater characteristics. This means that the most conventional treatment techniques have not meet up with the increasing global demand for clean water. In order to overcome the current water crisis globally especially in developing countries and at the same time achieve better economic gain, an alternative water reuse technologies are hence of paramount importance (Kathryn et al. 2009; Meńdez-Arriaga et al. 2010).

Due to increasing global concern for environment protection, the concept of advanced oxidation technologies for water and wastewater treatment was conceived. To date, studies still uphold advanced oxidation technologies (AOTs) as the most promising and highly competitive innovative water and wastewater treatment methods for the removal of biorecalcitrant compounds (Luiz et al. 2009; Oller et al. 2011; Sharma et al. 2011). AOTs stands as one of the viable technologies capable of decomposing biologically recalcitrant, persistent organic pollutants present in wastewater. The decomposition of environmental toxicants is easily accomplished by the formation of hydroxyl radicals. AOTs are not intended to replace conventional systems but to complement existing systems for better quality effluent. In the last couple of years, AOTs have attracted an increasing scientific attention especially in developed countries, though not commonly used in emerging nations due to high energy consumption and operating cost (Shannon et al. 2008). AOTs are based on physicochemical process that generates chemically reactive species at ambient temperature and pressure with or without catalyst and subsequently convert organic pollutants into carbon dioxide and water (Stasinakis 2008). Among the chemically active species produced by AOTs are ozone $\left(\mathrm{O}_{3}\right)$, hydrogen peroxide $\left(\mathrm{H}_{2} \mathrm{O}_{2}\right)$, singlet oxygen $(\mathrm{O})$, hydroxyl radical $\left(\mathrm{OH}^{*}\right)$, and others. However, $\mathrm{OH}^{*}$ is non-selective, unstable and the most reactive with highest oxidation potential of $2.33 \mathrm{~V}$ compared to other conventional oxidizing agents such as $\mathrm{O}_{3}, \mathrm{H}_{2} \mathrm{O}_{2}$, or $\mathrm{KMnO}_{4}$ whose oxidation potential are 2.07, 1.77, and 1.67 V, respectively (Gogate and Pandit 2004; Klavarioti et al. 2009). Investigations have shown that AOTs could be single or combined to purify water, but literature survey has shown that two or more treatment techniques are more beneficial and economical at the same time offers greater efficiency than the single-technology processing. Single advanced oxidation technology is not capable of completely eliminating the pollutants, instead it generates recalcitrants, inhibitory and intermediate by-products that are sometimes toxic than the parent compounds. In order to achieve complete decomposition of POPs present in wastewater, process combination rather than single-technology system is required. This will allow exploitation of the individual process strength and achieve the required target within a short reaction time and at a cheaper cost. However, in trying to design an effective system such as integrated advanced treatment process, it is imperative to take into cognisance the economic issue, individual system capacity, and perhaps physico-chemical properties of the wastewater. Studies have shown that the degradation efficiency of AOTs varies with respect to wastewater 
composition. Some systems are more effective than others due to difference in the quantity of the concentration of free reactive species generated. Information on the process combination is necessary in order to know individual system removal capacity and achieve overall process-efficient water treatment with minimum economic constraints. This opinion was substantiated in a review by Van Durme et al. (2008) and Oller et al., (2011) that integration of two destructive advanced oxidation processes are more beneficial conceptually. Despite the partial elimination of the pollutants by conventional wastewater treatment technologies including single advanced oxidation technology, surprisingly little or no review has ever focussed on the integration of two advanced oxidation technologies for the removal of organic pollutants. The information available in the literature shows that Scott and Ollis (1995) and Oller et al. (2011) have independently reviewed the combination of advanced oxidation technology with biological oxidation. However, the field of water purification and wastewater reuse is wide and it is not possible to review all conventional methods and various advanced oxidation techniques. To date, no extensive review has been published on the efficiency and effectiveness of the sequential combination of electrohydraulic discharge processes with photochemical oxidation or ultrasonic irradiation with photochemical oxidation processes as related to the removal of persistent organic pollutants from wastewater. Therefore, the present review focuses on the removal efficiencies and comparison of single and integrated advanced oxidation technologies as well as their limitations.

\section{An Overview of Different Advanced Oxidation Technology}

Advanced oxidation technology is one of the most environmental friendly techniques used to remove recalcitrant organic pollutants not easily treatable by existing conventional process due to their chemical stability. The degradation of biologically persistent pollutants occurs in the presence of highly reactive species such as ozone, hydrogen peroxide, and hydroxyl radicals at ambient temperature and pressure (Sharma et al. 2011; Oller et al., 2011). There are two types of AOTs as shown in Fig. 1. The two categories are further classified as either photochemical or non-photochemical processes. The basic mechanism of AOT is centered on the generation of highly reactive hydroxyl radicals. These hydroxyl radicals are unstable, nonselective, and powerful oxidants when compared to other known oxidizing agents like potassium permanganate. The hydroxyl radical reacts efficiently to fragment organic pollutants into harmless end products, $\mathrm{CO}_{2}$ and $\mathrm{H}_{2} \mathrm{O}$. Despite being a short-lived species, the hydroxyl radical attacked organic pollutants through hydrogen abstraction, electron transfer, and formation of a double bond with the organic compounds. 


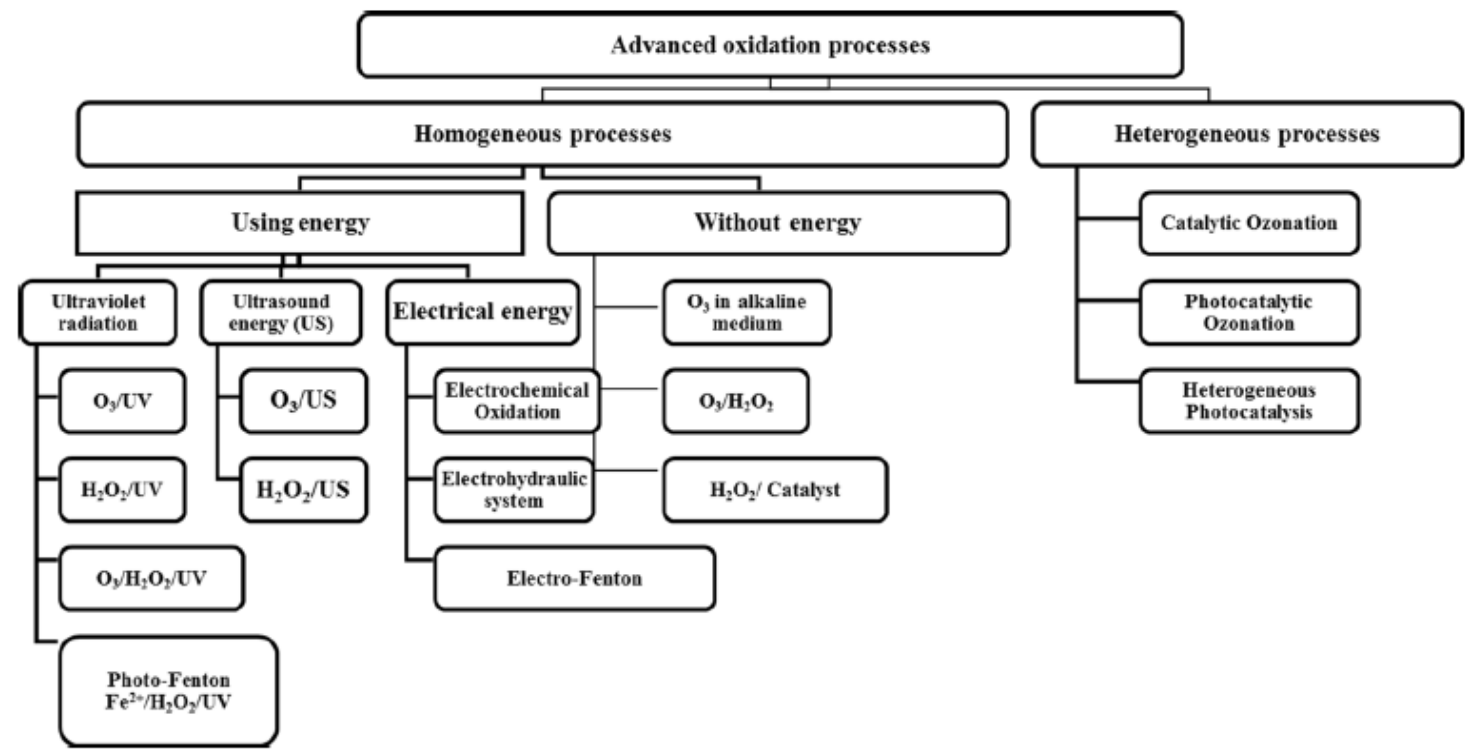

Fig. 1 Various AOTs based on wastewater treatment technologies (sourced from Sharma et al. (2011))

$$
\begin{aligned}
& \mathrm{R}+\mathrm{HO}^{*} \rightarrow \mathrm{ROH} \\
& \mathrm{R}+\mathrm{HO}^{\cdot} \rightarrow \mathrm{R}^{\cdot}+\mathrm{H}_{2} \mathrm{O} \\
& R_{n}+\mathrm{HO}^{\cdot} \rightarrow R_{n-1}+\mathrm{OH}^{-}
\end{aligned}
$$

Among different AOTs, Fenton and photo-Fenton for the removal of organics from wastewater have been extensively reviewed and thus have received greater attention than any other AOTs in recent years (Gogate and Pandit 2004). This was substantiated by Maletz et al. (2013) in the survey of articles and abstract available online from more than 15,475 international journals and other science scholar database. It is on this basis that other AOTs such as electrohydraulic discharge process, heterogeneous photocatalysis, and ultrasonic irradiation were considered and reviewed accordingly.

\subsection{Electrohydraulic Discharge Treatment in Water}

Electrohydraulic discharge system is regarded as one of the advanced oxidation technologies widely applied for water and wastewater treatment to inactivate microbes and degrade toxic or hazardous pollutants (Malik 2010; Jiang et al. 2014). There are various forms of electrical discharge plasma produced either in water or above water such as in gas phase contacting the liquid. This review considered high-voltage electrical discharge directly in water shown in Fig. 2, otherwise called electrohydraulic discharge (HER). This technology is widely considered due to non-addition of external chemicals, environmentally compatibility, effectiveness, simplicity of operation at ambient temperature and pressure (Johnson et al. 2003; Sun et al. 2000; Locke et al. 2006; Sato et al. 2008; Even-Ezra et al. 2009; Krause et al. 2009; Zhang et al. 2013; Jiang et al. 
2014). Other advantages of corona discharge system include greater efficiency, nongeneration of secondary pollution, ability to kill microbes, and high efficiency (Chen et al. 2008).

However, high consumption of electricity (alternate or direct current) when compared to other wastewater treatment methods hinder its full-scale commercialization. Even though alternate energy source such as solar light could be used, the cost of installation and maintenance is somehow cumbersome. However, detailed economic analysis such as operating, capital, and equipment costs are not included in this review. The application of under-water electrical discharge for industrial wastewater treatment is limited due to the aforementioned technical challenges (Jiang et al. 2014). The use of electrical energy to treat drinking and polluted water commenced after Clements et al. (1987) demonstrated that high-voltage electrical discharge in water forming plasma could decolorize and decompose dye molecules. The degradation mechanism of target pollutants is akin to water droplets from the atmosphere. Ever since then, underwater electrical discharges have continued to be investigated for medical, material functionalization, water treatment and disinfection processes (Bruggeman and Locke 2013).

Fig. 2 Schematic diagram of the electrohydraulic discharge system

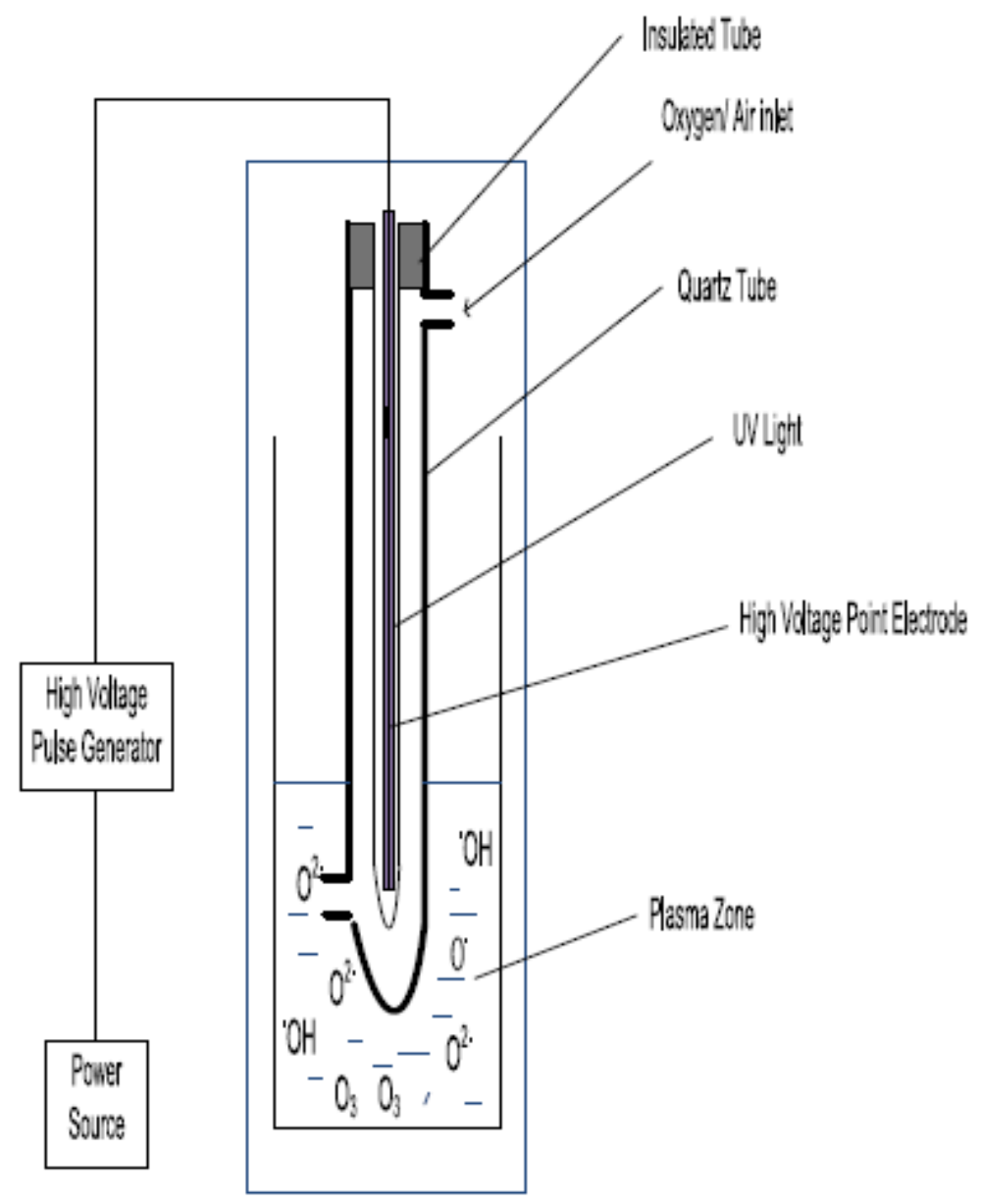

Several laboratory studies and review articles by different research groups have indeed focussed on the applications of electrical energy to water treatment. There are different categories of electrical discharge systems for water treatment depending on the relative magnitude of

\section{http://repository.uwc.ac.za}


applied energy in the system. The efficiency or reactivity of the plasma generation systems vary with respect to reactor configuration, energy yield, and sometimes depend on the input energy, liquid properties and excitation voltage (Malik 2010; Jiang et al. 2014). Apart from the above factors, energy yield often depends on the electron density, pollutants structure, nature and concentration of pollutants, temperature, electrode material, the extent of transformed products, solution $\mathrm{pH}$ and sometimes conductivity. Another factor is pulse repetition rate of input power on the properties of pulsed high-voltage discharges in water (Ruma Lukes et al. 2013). The roles played by many of these factors are not obviously known as most of them are strongly interrelated with respect to overall reactor performance. Currently, most studies are focusing on how to improve the energy yield of a plasma reactor. Although, the energy yield of each reactor vary over a wide range due to difference in the reactor type experiment conditions used by the different research group globally. Their findings indicate a dramatic variation in the efficiency of different types of plasma reactors and as such the difference is close to 5 orders of magnitude (Malik 2010). In same vein, limited data on energy yield of plasma reactors exist because of the differences in the reactor type used by various research group globally. Another factor affecting the energy yield of different plasma reactor is the formation of intermediates. The physical and chemical processes within the discharge convert the pollutants into various intermediates. Secondary reaction often occurs where the plasma formed in the gas phase seems to be most efficient than in the liquid phase.

Table 1 Some characteristics of different electrohydraulic discharges

\begin{tabular}{lll}
\hline Parameters & \multicolumn{2}{l}{ Value } \\
\cline { 2 - 3 } & Pulsed corona & Pulse arc \\
\hline Operating frequency & $10^{2}-10^{3} \mathrm{~Hz}$ & $10^{-2}-10^{-3} \mathrm{~Hz}$ \\
Current (peak) & $10-10^{2} \mathrm{~A}$ & $10^{3}-10^{4} \mathrm{~A}$ \\
Voltage (peak) & $10^{4}-10^{6} \mathrm{~V}$ & $10^{3}-10^{4} \mathrm{~V}$ \\
Voltage rise & $10^{-7}-10^{-9} \mathrm{~s}$ & $10^{-5}-10^{-6} \mathrm{~s}$ \\
Pressure wave generation & Weak to moderate & Strong \\
UV generation & Weak to moderate & \\
\hline
\end{tabular}

Sourced from Chang et al. (2002) and Locke et al. (2006)

This is because higher energy is needed for the electrical discharge to happen in liquid than that in a gas phase; at the same time, water is denser and highly polar with specific conductivity than gases. Furthermore, much of the energy is consumed during mechanical and thermal heating processes (Locke and Thagard 2012). Also, direct discharge in bubbles inside liquid water is also more active and efficient than direct liquid spark or even corona discharge. This is due to the production of a reactive hydrogen peroxide. In spite of the above, the detailed mechanism of electrical discharge in water still remains largely 
unknown, while deep understanding regarding discharges in gas phase such as one-, two-, and three-dimensional streamer propagation models combined with ionization and chemical processes that took place within the plasma zone have been developed (Lukeš 2001). To avoid this ambiguity, Magureanu et al. (2010) and Lukes et al. (2011) designed a new reactor where corona discharges occurred in gas phase though very close to the contaminated water. This however raises a lot of questions and generates concern regarding the system efficiency since active species between water and gas boundary layer occupied a small space. This constraint was reduced via the discharge of the generated plasma fully in water. Different kinds of electrical discharges are produced either directly in water or above the water surface for water treatment. At the same time, various reactors geometries and electrode configurations have been designed and applied for wastewater treatment (Magureanu et al. 2008a, 2010). The following types have been mostly identified such as corona or pulse electrohydraulic discharge reactor, pulsed spark electrohydraulic discharge reactor, pulsed arc electrohydraulic discharge reactor, and pulsed power electrohydraulic discharge reactor (Locke et al. 2006). Each of these has been extensively reviewed. For more information, the readers are referred to the following review article (Locke et al. 2006; Malik 2010). In electrohydraulic discharge techniques, the introduction of air or pure oxygen into the reactor produces ozone. It has been established that the presence of ozone with the plasma zone significantly increase the decomposition rate due to the formation of hydroxyl radical formed by the reaction of UV light with ozone. In addition, the intensity of shock wave, UV light, amount of bubbles, and reactive species varies with reactor types. The step-by-step formation of each active species within the reactor is shown in the equations below 
Dissociation

$\mathrm{H}_{2} \mathrm{O}+\mathrm{e} \rightarrow \mathrm{OH}^{\cdot}+\mathrm{H}^{\cdot}+\mathrm{e}$

Ionization: $\mathrm{H}_{2} \mathrm{O}+\mathrm{e} \rightarrow 2 \mathrm{e}+\mathrm{H}_{2} \mathrm{O}^{+}$

Dissociation: $\mathrm{H}_{2} \mathrm{O}^{+}+\mathrm{H}_{2} \mathrm{O} \rightarrow \mathrm{OH}^{\cdot}+\mathrm{H}_{3} \mathrm{O}^{+}(6)$

$\mathrm{H}_{2} \mathrm{O}+\mathrm{e}^{-} \rightarrow \mathrm{OH}^{\cdot}+\mathrm{H}^{\cdot}+\mathrm{e}^{-}$

$\mathrm{OH}^{*}+\mathrm{OH}^{\cdot} \rightarrow \mathrm{H}_{2} \mathrm{O}_{2}$

$\mathrm{H}_{2} \mathrm{O}_{2}+\mathrm{hv} \rightarrow 2 \mathrm{OH}^{*}$

$\mathrm{OH}^{\cdot}+\mathrm{H}_{2} \mathrm{O}_{2} \rightarrow \mathrm{H}_{2} \mathrm{O}+\mathrm{HO}_{2} \cdot$

$\mathrm{HO}_{2}{ }^{*}+\mathrm{H}_{2} \mathrm{O}_{2} \rightarrow \mathrm{O}_{2}+\mathrm{H}_{2} \mathrm{O}+\mathrm{OH}^{*}$

$2 \mathrm{O}_{3}+\mathrm{H}_{2} \mathrm{O} \rightarrow \mathrm{OH}^{*}+\mathrm{O}_{2}+\mathrm{HO}_{2}{ }^{*}$

$\mathrm{O}_{3}+\mathrm{hv} \rightarrow \mathrm{O}_{2}+\mathrm{O}\left({ }^{1} \mathrm{D}\right)$

$\mathrm{O}\left({ }^{1} \mathrm{D}\right)+\mathrm{H}_{2} \mathrm{O} \rightarrow 2 \mathrm{OH}^{*}$

$\mathrm{O}_{3}+\mathrm{HO}_{2}^{-} \rightarrow \mathrm{HO}_{2}{ }^{\cdot}+\mathrm{O}_{3}{ }^{-}$

$\mathrm{O}_{3}{ }^{--}+\mathrm{H}_{2} \mathrm{O} \rightarrow \mathrm{OH}^{*}+\mathrm{OH}^{-}+\mathrm{O}_{2}$

Until today, very few studies focused on the chemical effects of the shock wave, induced cavitation, and UV light on the degraded pollutants. It is essential to characterize these effects especially UV light impacts within the plasma channel since UV radiation is one of the energies discharge in water from high-voltage electrical source (Joshi and Thagard 2013). The performance of different plasma reactors as well as the factors affecting the plasma discharge has been documented (Locke et al. 2006; Malik 2010; Jiang et al. 2014). This review will not

\section{http://repository.uwc.ac.za}


cover the parameters influencing the rate of discharge since this has been adequately covered by Jiang et al. (2014). Studies have shown that electrohydraulic discharge system can remove and degrade priority pollutants (Locke et al. 2006; Sato et al. 2008; Krause et al. 2009; Zhang et al. 2013). The degradation efficiency may be enhanced in combination with heterogeneous photocatalysis or other AOTs. The choice of one method over the other depends upon the number of factors such as wastewater characteristics, goals of the treatment, temperature, pH, conductivity, and suspended solids (Bruggeman and Locke 2013). Available information from literature indicates that no single technology is efficient to remove all kinds of contaminants, and the common practice requires a combined approach. In trying to couple treatment processes, economic feasibility, system compatibility, and energy cost should be taken into consideration and perhaps carry out comparative studies with the existing conventional and alternative methods. Electrohydraulic discharge system for instance can be coupled with catalyst, carbon material, metal oxide, metal ions, and other catalyst in order to improve the overall process efficiency and perhaps plasma degradation process. The high electric field generated as a consequence of high-voltage electrical discharge for instance reduced the recombination rate of electron- hole pairs on the surface of $\mathrm{TiO}_{2}$ and enhance the catalysts performance. In addition, the electric field, ultrasonic irradiation, and shock wave generated within the reactor also aids in the cleaning and sweeping of the $\mathrm{TiO}_{2}$ surface. This eventually hastens the mass transfer of the pollutants onto the solid catalyst surface. Thus, integration of plasma technologies with photochemical oxidation may improve their treatment performance and, at the same time, overcome some of their individual shortcomings (Jiang et al. 2014).

However, the degradation efficiency of combined system depends on the nature of treated wastewater in question. Scott and Ollis (1995) highlighted four categories of wastewater contaminants namely: recalcitrant compounds, largely biodegradable compounds, inhibitory compounds, and intermediate byproducts. Thus, the performance of integrated process may be dramatic, modest, negligible, or adverse depending on the reaction conditions and the nature of wastewater in question. Dobrin et al. (2013) utilized pulsed corona discharge generated above liquid to degrade diclofenac in water. The results as presented indicated that, only $50 \%$ of the compound decomposed after 30 min of exposure to plasma. Leitner Karpel Vel et al. (2005) demonstrated the removal of atrazine by pulsed arc electrohydraulic discharge (PAED) system from wastewater. The discharge was produced via spark gap type with a power supply (0.5 kJ/pulse) using rod-torod type electrodes in water. However, most physical parameters indicated that the discharge was characterized with voltage drop with occurrence of a peak current. Despite this, there was formation of by-products (deethylatrazine), and the author concluded that an increase in electrode gap beyond $2.5 \mathrm{~mm}$ enhanced the decomposition efficiency. This shows that pulse arc electrohydraulic discharge is not efficient enough to degrade atrazine. In the same vein, Zhang et al. (2012) utilized a pulsed high-voltage discharge system to eliminate 2,4- dichorophenol (2,4-DCP) from aqueous solution. The study showed that the rise in peak voltage from 18 to $26 \mathrm{kV}$ with a corresponding energy input from 0.0057 to $0.0397 \mathrm{kWh}$ was responsible for the rise in degradation efficiency from 58 to $99 \%$ within 42 min. Low $\mathrm{pH}$ value and salt content of the solution were recognized as the possible factors 
thwarting the degradation of the modeled pollutant. The degradation efficiency could be improved via increase in pulsed voltage and frequency. Hydroxyl radical dominated and reacted with 2,4-dichlorophenol forming series of intermediate by-products such as 3,5-dichloro-1, 2benzenediol, 2- chlorohydroquinone, and 1,2,4-trihydyoxybenzene including 2,4-hexadienal, maleic acid, and formic acid as detected by GC-MS. Reddy et al. (2012) applied corona discharge system to remove and degrade crystal violet. Hydroxyl radical was responsible for the degradation of crystal violet. In addition, increase in energy input contributed to reduction of total organic carbon. Magureanu et al. (2010) utilized dielectric barrier discharge (DBD) system to degrade pentoxifylline in aqueous solution. Ninety-two percent removal of pentoxifylline was achieved after 60 min of plasma treatment. The degradation efficiency decreased with increase concentration of pentoxifylline. Zhang et al. (2009) demonstrated the use of pulsed corona discharge for methyl orange (MO) removal from aqueous solution. The decolorization rate of MO was found to depend on the peak voltage, pulsed frequency, methyl orange concentration, and gas type. Whereas, increase in the peak voltage and pulsed frequency with a corresponding solution conductivity positively influenced the percentage of methyl orange removed. However, the bubbling of oxygen gas into corona discharge system improved the degradation rate. Krause et al. (2009) studied the degradation of carbamazepine, clofibric acid, and iopromide in water using corona discharge. The modeled pollutants were effectively degraded by corona system after $30 \mathrm{~min}$, and the E-Screen assay also confirmed that iopromide degradation products were no longer estrogenic after $15 \mathrm{~min}$ of treatment. Bian et al. (2011) applied pulsed high-voltage discharge to decompose 4-chlorophenol in water. The degradation process was accompanied with the formation of intermediate products forming hydroquinone, 4-chlororesorcinol, and 4chlorocatechol. Other intermediates identified include formic, acetic, oxalic, malonate, maleic, and malic acids. Although, more of 4-chlorocatechol was formed than hydroquinone and 4chlororesorcinol. The possible degradation pathways for the intermediates and other ringopening compounds were proposed. The initial degradation step was hydroxylation despite direct cleavage products observed at $\mathrm{C}(1)-\mathrm{C}(2)$ or $\mathrm{C}(5)-\mathrm{C}(6)$ bond. Within $36 \mathrm{~min}$ of the discharge, more than $50 \%$ mineralization of the carbon compounds obtained from organic acids were observed, while less than $20 \%$ of the carbon from aromatic products equivalent to about $94 \%$ of initial carbon was removed. However, after 60 min of discharge, 4-chlorophenol and its aromatic intermediates were removed completely leaving behind the organic acid such as acetic and oxalate acids. With prolong discharge to $120 \mathrm{~min}$, $86 \%$ degradation was achieved leaving behind $14 \%$ of the initial carbons. In a related study, Krause et al. (2011) reported the removal of carbamazepine, clofibric acid, and iopromide in aqueous solution using corona discharge containing with two-barrier electrodes above a rotating drum that acts as the counter electrode. In fact, in a single solution with a power output of $500 \mathrm{~W}$, the removal of clofibric acid was below the detection limit after $30 \mathrm{~min}$ of treatment time, while carbamazepine and iopromide removal was between 94 and $98 \%$ after 60 min. However, in a leachate landfill solution with the same output power, $97 \%$ mineralization of carbamazepine and $88 \%$ clofibric acid degradation was achieved after $90 \mathrm{~min}$, and iopromide to $19 \%$. However, the degradation kinetics, with respect to output power level, revealed that iopromide was the greatest, while with carbamazepine showed the least. The authors observed that the degradation rates of the pollutants were enhanced as 
the power output, rotational speed, and electric field increased. The reduction in the air gap to $1.5 \mathrm{~mm}$ was responsible for the formation of more reactive species. Lei et al. (2007) used pulse high-voltage discharge system to degrade 4-chlorophenol in aqueous solution. The experiment was conducted as a function of electrode distance, liquid conductivity, initial concentration of the pollutants, and contact time. The results indicated that more than $95 \%$ of the target pollutants were removed, and the mineralization of total organic carbon (TOC) reached 55.8 \%. 4-Chlorocatechol, hydroquinone, 5-chloro-3-nitropyrocatechol, chloride ion, formic, and acetic and oxalic acids were identified as intermediate products. The kinetic model fitted well to the proposed mathematical model. In the same vein, Bian et al. (2009) investigated the degradation of $p$-chlorophenol by a novel pulsed high-voltage discharge reactor. The authors discovered that in the absence of oxygen, low concentration of reactive oxygen species such as ozone, hydrogen peroxide, and hydroxyl radical were observed. This resulted to low degradation efficiency as there were not enough radicals to decompose the modeled pollutants. Although, there was an increase in the concentration of active species when oxygen was introduced to the reactor. Within $36 \mathrm{~min}$ of reaction, $97 \%$ of the modeled compound was removed. This in turn lowered the $\mathrm{pH}$ of the solution and subsequently increased the solution conductivity. In another study, Bian and Lee (2007) developed a saltresistant electro-hydraulic discharge system to degrade $p$-chlorophenol. They reported that the passage of gas within the discharge zone decreased the salt content, whereas, in the absence of gas, the salt level with the reactor increased significantly. Subsequently, more reactive species were produced, and that, perhaps, was responsible for the decomposition of $p$-chlorophenol. More so, Lockes et al. (2013), in their study, revealed that the corona discharge technique alone degraded more than $95 \%$ of recalcitrant organics pollutants, thus minimizing the use of chemicals in wastewater treatment. The complete degradation of the contaminants was ascribed to the reactive species generated by corona discharge, producing UV irradiation in the water. Wahyudiono et al. (2013) utilized pulsed discharge plasma over water to decolorize orange G, orange II, Congo II, and Naphthol blue black. The results as presented revealed that the rate of decolorization of the dyes increases with rise in peak pulse voltage and pulse number. The maximum mineralization rate of 50.05, 41.64, 44.98, and $53.25 \%$ correspond to orange G, orange II, Congo II, and Naphthol blue black, respectively. Zhang and Sun (2006) reported that the degradation of methylene blue by a pulse discharge reactor was dependent on the peak voltage and repetition frequency, treatment time, and hydrogen peroxide concentration. The decoloration of methylene blue was low when treated with hydrogen peroxide alone; however, there was a rapid improvement in the decoloration of methyl blue when hydrogen peroxide was combined with the discharge. In fact, the decoloration efficiency of $91.44 \%$ was obtained due to the combined treatment as compared to 47.71 and $3.96 \%$ obtained from the individual treatment. Zhu et al. (2013) found that an increase in the discharge voltage or pulse frequency is directly proportional to removal rate of phenol. Equally, increase in oxygen flow rate is proportional to the rate of removing phenol from water.

The energy efficiency and minimization of economic cost of the electrohydraulic discharge system lay in its combinatory role with other AOTs particularly photocatalysis. To buttress this fact, Scott and Ollis (1995) submitted that process integration is more beneficial 
and economical for wastewater treatment than single-technology processing. The authors further found that biological pretreatment of the wastewater improve the overall efficiency of the integrated process. Although, the authors admitted that coupling of chemical and biological process in one way or another is a difficult tasks during investigations and even when operating at a full-scale plant. Jiang et al. (2014) also affirmed that the improvement of energy efficiency lies in the coupling of plasma technology with heterogeneous photocatalysis. Thus, integration of electrohydraulic discharge reactor ( EHDR) with heterogeneous photocatalyst will enhance the degradation efficiency compared to single advanced treatment option ( $\mathrm{Li}$ et al. 2007; Wang et al. 2008a; Okolongo Gauthier et al. 2012a, b, c). The semiconductor photocatalyst utilizes the ultraviolet produced during plasma discharge. The incorporation of $\mathrm{TiO}_{2}$ nanocomposites into electrohydraulic discharge system, thus, enhanced the photocatalytic activity of semiconductor metal oxide via dramatic shift in the electron distribution (Wang et al., 2008). Zhang et al. (2013) found that the degradation efficiency of Indigo Carmine solution was enhanced when bipolar pulsed discharge plasma was combined with $\mathrm{TiO}_{2}$ photocatalyst. In fact, complete decolorization occurs within the first $3 \mathrm{~min}$. Also, the integration of corona discharge with heterogeneous semiconductor metal oxide according to Chavadey et al. (2007) contributed to the generation of the superoxide radical anion $\left(\mathrm{O}^{2-}\right)$ responsible for the degradation of the pollutant. Lang et al. (1998) found that combination of electrohydraulic discharge and ozonation technique accelerated the degradation of 2,4,6-trinitrotoluene (TNT) in aqueous solution. In fact, more than $90 \%$ of the pollutant was mineralized over the course of 300 electrical discharges of 7 $\mathrm{kJ}$ within $12 \mathrm{~min}$. This was attributed to the increased concentration of hydroxyl radicals during the reaction of UV light in the reactor chamber with $\mathrm{O}_{3}$. $\mathrm{Li}$ et al. (2007) found that incorporation immobilized $\mathrm{TiO}_{2}$ nanocomposite into pulsed streamer discharge system enhanced the degradation rate by $16.7 \%$. The authors ascribed the increase degradation rate to production of more reactive radicals by the two processes. They concluded that a synergy exist between the two system. Magureanu et al. (2013) reported that decolorization of 50 $\mathrm{mg} / \mathrm{l}$ of methylene blue solution was observed within $10 \mathrm{~min}$ of exposure to pulsed corona discharge system. The addition of $5 \mathrm{mg} / \mathrm{l} \mathrm{FeCl}_{2}$ accelerated the decomposition of methylene blue, and complete decolorization was achieved within $3 \mathrm{~min}$. The authors attributed the observed phenomenon to increased formation of hydrogen peroxide. Lukes et al. (2005) demonstrated that the pulse corona discharge system combined with powder $\mathrm{TiO}_{2}$ photocatalysts successfully eliminated and degraded phenol. The removal efficiency was enhanced in the presence of $\mathrm{TiO}_{2}$. In a related study, Manoj Kumar Reddy and Subrahmanya (2012) established that the degradation and mineralization of crystal violet by arc discharge plasma was due to the presence of the generated active species such as hydroxyl radicals, hydrogen peroxide, and UV. The addition of $\mathrm{Fe}^{2+}$ enhanced the decomposition rate of crystal violet. Shang et al. (2010) studied the degradation of phenol by combined pulsed corona discharge and powder photocatalysts. The degradation rate was dependent on the catalyst dosage, crystal size, as well as catalyst structure. It was reported that an increase in $\mathrm{TiO}_{2}$ dosage increases the number of reactive oxidants responsible for pollutant decomposition. Besides, rapid degradation of phenol as well as total organic carbon removal 
was noticed. Hence, the authors concluded that a synergy existed between pulse corona discharge and heterogeneous photocatalysis as regards phenol degradation. Lian et al. (2011) demonstrated the degradation of acid red 8 by combined high-voltage corona discharge system and ozonation. They found that the degradation rate was raised by $25 \%$ when the two techniques were coupled compared to when the individual technique was used. Hence, the combined systems represent a better technology for treating wastewater containing acid red 8. In another effort, Hao et al. (2007) established that there was a synergy between the powder $\mathrm{TiO}_{2}$ photocatalysts and nonthermal plasma system during the degradation of $4^{-}$ chlorophenol, phenol, and methyl red in water. The authors revealed that incorporation of the $\mathrm{TiO}_{2}$ photocatalyst into the nonthermal discharge process did not only increase the chemically active species but effectively enhanced the degradation and mineralization efficiency rate. Also, the comparative study on the degradation of 4-chlorophenol and 4nitrophenol with three pulse electrical discharge system was investigated by Dang et al. (2009). The authors submitted that pulsed corona discharge eliminated the modeled pollutants more efficiently than the spark and streamer corona discharge. This was attributed to the amount of energy released during the discharge. The addition of ferrous ions assisted in the proper understanding of the degradation mechanistic pathways. Gerrity et al. (2010) utilized nonthermal plasma discharge process to remove carbamazepine, trimethoprim, meprobamate, primidone, and atrazine from tertiary-treated wastewater. The experiment was conducted as functions of $\mathrm{pH}$, alkalinity, total organic carbon, interaction time, concentration of the pollutants, and applied voltage. The authors observed an increase in the electrical energy per order (EEO) of magnitude degradation for the easily degraded (carbamazepine) and more recalcitrant compounds (meprobamate) in surface water from <0.3 to $14 \mathrm{kWh} / \mathrm{m}^{3}$-log, respectively. The authors concluded that nonthermal plasma could serve as an alternative to other AOTs as a result of comparable energy use for pollutants degradation and its capacity to work effectively without any chemical addition. Sein et al. (2012) investigated the plasma formation potential of two parallel electrodes submerged in water in relation to the quantity of $\mathrm{H}_{2} \mathrm{O}_{2}$ formed. It was however discovered that plasma formation alongside hydrogen peroxide was dependent on solution conductivity and $\mathrm{pH}$. Extensive plasma discharge was reported to cause electrode corrosion and a decrease in hydrogen peroxide quantum yield. Hence, $\mathrm{Al}_{2} \mathrm{O}_{3}$-coated electrode with a thickness of $100 \mu \mathrm{m}$ was recommended if a stable plasma and better energy efficiency were to be obtained. Zhang et al. (2012) explored the combined pulsed plasma discharge and powder $\mathrm{TiO}_{2}$ photocatalysts to decompose phenol. About $88.8 \%$ phenol was removed by pulsed plasma discharge alone and $\mathbf{1 1 . 2} \%$ increase in mineralization efficiency was noted when powder $\mathrm{TiO}_{2}$ photocatalysts were incorporated. The incorporation of a $\mathrm{TiO}_{2}$ nanotube film improved the degradation rate of phenol as well as reduced the reaction time. In the same vein, Zhang et al. (2013a) compared the efficiencies of two pulse discharge system coupled with $\mathrm{TiO}_{2}$ photocatalysts on phenol decomposition. They realized the degradation efficiency was higher when the discharge reactor cylinder (CTD) was combined with $\mathrm{TiO}_{2}$ photocatalysts in film form than when a single discharge system was used. Surprisingly, the photocatalytic activity and stability was maintained even after repeated applications, and the decomposition rate of phenol still remained the same. Thus, combined treatment

\section{http://repository.uwc.ac.za}


involving CTD and a $\mathrm{TiO}_{2}$ film has a higher degree of efficiency with respect to phenol degradation in wastewater. Manoj Kumar Reddy et al. (2013) reported the removal of methylene blue from aqueous solution using nonthermal plasma discharge. The authors found that almost $67 \%$ degradation rate of methylene blue was observed; however, addition of $\mathrm{Fe}^{2+}$ improved decomposition rate. Zhang et al. (2013b) equally demonstrated the integration of $\mathrm{TiO}_{2}$ nanotubes with pulse corona discharge to degrade phenol in aqueous solution. They reported that with pulse corona discharge, only $60 \%$ phenol removal was achieved; nevertheless, with the incorporation of $\mathrm{TiO}_{2}$ nanotubes film, the removal time was short and a dramatic increase of about $98 \%$ degradation efficiency was observed. Zhang et al. (2011) studied the catalytic potentials of three granular activated carbons (GAC1, GAC2, and GAC3) combined with a pulsed discharge reactor on methyl orange degradation. The authors noted with pulse discharge treatment alone that about $84 \%$ of methyl orange was removed. However, when combined with GAC1 or GAC2 and GAC3, the removal efficiency increased to 96.3, 92.0, and 95.4\%, respectively. This suggests that the integrated treatment has synergistic effect. The synergistic effect for GAC1 and $\mathrm{GAC}_{3}$ took place within the first 9 min with degradation efficiency of 90 and $89.5 \%$, respectively. Only $53.8 \%$ removal rate was noticed in the absence of GAC under the same condition. For GAC2, the synergistic effect occurred in the first $12 \mathrm{~min}$ and the degradation efficiency achieved was $82.8 \%$; while with pulse discharge treatment alone, only $65.7 \%$ removal in the same processing time was noticed. The catalytic ability of the granular-activated carbon according to the authors might be due to the presence of functional group, narrow pore size distribution, and high specific surface area, which prompted ozone dissociation in aqueous media, and perhaps generates hydroxyl radicals. Similarly, Zhang et al. (2010) applied titanium dioxideloaded activated carbon fiber in a pulsed discharge reactor to degrade methyl orange. The influence of solution $\mathrm{pH}$ and conductivity on the combined treatment was evaluated. The authors revealed that more oxygen-containing species such as hydroxyl radicals were formed when activated carbon fibers were integrated with pulse corona discharge. With activated carbon fiber/ $/ \mathrm{TiO}_{2}$ alone, $61.3 \%$ methyl orange removal was obtained. Likewise with pulsed discharge alone, $63.0 \%$ methyl orange degradation was reached. However, when the two systems were combined, the degradation rate increased to $98.2 \%$. There was a corresponding increase in the energy efficiency of the combined system increased by $58.2 \%$. This shows that there is a synergistic effect between the two processes. Shen et al. (2008) demonstrated the decomposition of phenol by pulsed electrical discharges. They investigated the degradation efficiency of phenol under the influence of some gases (such as oxygen, argon, nitrogen, and ozone) and chemical oxidant species (like ferrous ion and hydrogen peroxide). They observed that the highest decomposition rate was obtained when oxygen-containing ozone was bubbled through the reactor. The order of phenol degradation was as follows: oxygencontaining ozone > oxygen>argon> nitrogen and the degradation pathway ensued with or without the chemical oxidants. The addition of ferrous ion enhanced the decomposition rate of the modeled pollutants. In another related study by Hao et al. (2013) where the impact of metal ions on the degradation of 4-chlorophenol by pulsed discharge plasma was investigated, it was established that among the four metal ions such as $\mathrm{Fe}^{2+}$, 
$\mathrm{Fe}^{3+}, \mathrm{Cu}^{2+}$, and $\mathrm{Mn}^{2+}$ studied, ferrous ions significantly improved the degradation efficiency compared to the other metal ions.

Furthermore, Table 2 shows the removal of priority organic compounds, the experimental conditions, and results by single and combined electrohydraulic discharge system. In summary, the difference between single techniques and combined treatment are stated clearly, with the combination approach appearing to be more promising in both organic pollutants elimination and degradation. With combined approach, increase in energy yield and overall removal efficiency was observed. This makes the combined electrohydraulic discharge system for water reclamation a feasible substitute for commercialization in the nearby future. It was generally observed that complete degradation cannot be achieved by electrohydraulic discharge system alone, instead intermediate by-products were generated. Because complete mineralization was not achievable with single AOTs, integrated AOTs system was subsequently favored. These coupled systems effectively enhanced the rate of degradation, eliminating the generation of by-products. Also noteworthy of mentioning from Table 2 is the energy yields which vary with respect to the target pollutants. This, according to Bruggeman and Locke (2013), depends on the nature of electrical discharge methods. For instance, a study conducted by $\mathrm{Li}$ et al. (2007) showed that $95 \%$ removal of 4-chlorophenol was achieved with- in 90 min using pulse high-voltage discharge system. The total organic carbon (TOC) indicated that only $55.8 \%$ of the compound decomposed. Four different byproducts such as hydroquinone, 4-chlorocatechol, 5-chloro-3-nitorpyrocatechol, and oxalic acid were identified. In the same vein, the decomposition of carbamazepine, clofibric acid, and iopromide by corona discharge alone was accompanied with the formation of by-products. This occurred as a consequence of partial degradation; only 40 $\%$ degradation of iopromide was achieved while carbamazepine and clofibric acid degradation were close to 100. Similar trend were noticed during the degradation of carbamazepine, trimethoprim, meprobamate, primidone, and atrazine by nonthermal plasma discharge techniques (Gerrity et al. 2010). In addition, Wang et al. (2008b) combined corona discharge and powder $\mathrm{TiO}_{2}$ photocatalyst to degrade phenol. Neither of the individual systems was able to achieve complete degradation, but with an integrated system, complete elimination of the target pollutants was possible. 


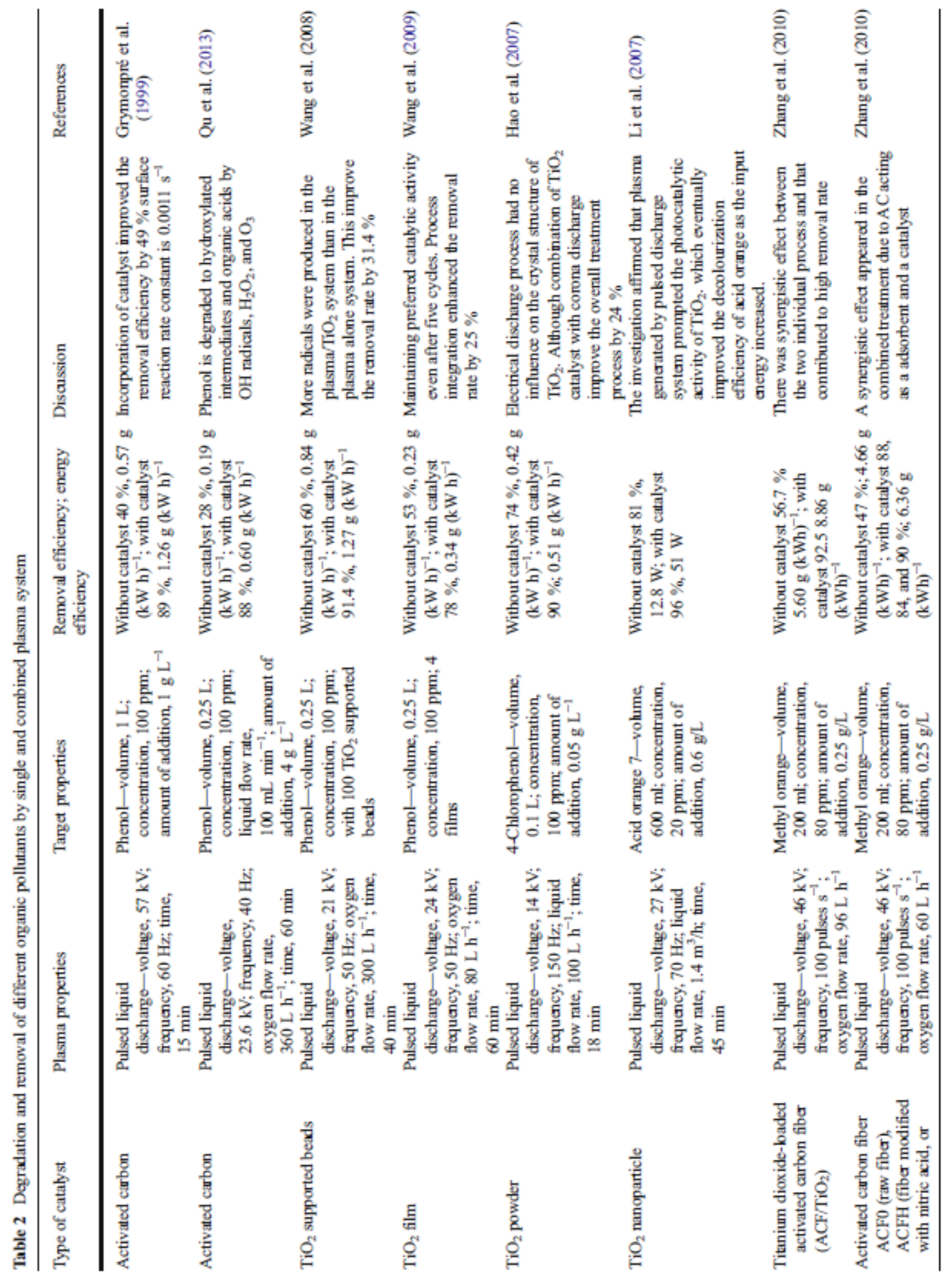




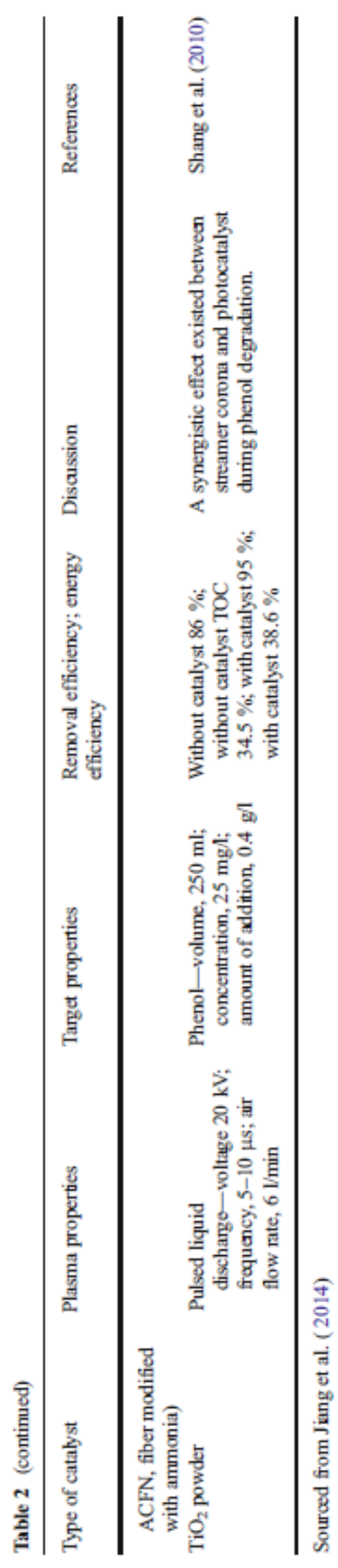

Zheng et al. (2013) utilized the combined technology of ozone and high-voltage pulse corona discharge to degrade $p$-nitrophenol in aqueous solution. It was observed that within $30 \mathrm{~min}, 96 \%$ decomposition rate of $p$-nitrophenol occurred. This combined 
technology of using two individual processes in series indicates that synergistic effect existed between high-voltage pulse corona discharge and ozone. Hence, in spite of the fact that combined treatment technique are yet to be widely explored, the system represents one of the most beneficial treatment processes for the abatement of priority organic pollutants from the environment. The performance of electrohydraulic discharge system alone either in the laboratory or semipilot plants has been satisfactory. Therefore, its combination with other AOTs especially heterogeneous photocatalysis offer hope for real applications in the near future.

\subsection{Photochemical Oxidation}

Among the advanced oxidation technologies, heterogeneous photocatalysts involving the use of $\mathrm{TiO}_{2}$ have been systematically considered in the last couple of years due to their capability in solar energy conversion and environmental wastewater purification (Wang et al. 2008c; Klavarioti et al. 2009; Chong et al. 2010). The photocatalytic process encompasses the capturing of photoenergy (hv) by the photocatalysts such as $\mathrm{TiO}_{2}$ to produce electron excitation (Palominos et al. 2008; Klauson et al. 2010; Elmolla and Chaudhuri 2010). The mechanism of the formation of electron-hole pairs on the semiconductor photocatalyst metal oxide surface $\left(\mathrm{TiO}_{2}\right.$ in particular) through a series of redox reactions (Fig. 3) and eventual generation of hydroxyl radicals have described in the literature (Ahmed et al. 2010; Chong et al. 2010; Homem and Santos 2011). The interaction of catalyst surface with the photoenergy gives rise to a sequence of reaction steps and pathways have been widely reported (Chong et al. 2010). Titanium (IV) oxide, often referred to as titania, titanium white, titanic anhydride, or titanic acid anhydride occurs naturally as an oxide of titanium. It exists in four different polymorphs namely rutile, anatase, brookite, and titanium (IV) oxide B. These three crystal structures differ appreciably from one another through the bond angle distortion of the octahedral chains. And among three polymorphs, anatase and rutile are photocatalytically active and rutile is the most thermodynamically stable phase. Anatase sometimes mixed with rutile in order to decrease high photogenerated electron-hole recombination rate (Dalrymple et al. 2007). 
Fig. 3 Mechanism of electronhole pair formation in a $\mathrm{TiO}_{2}$ particle in the presence of pollutants in water (sourced from Chong et al. (2010) and Muhammad and Hamidi Abdul Aziz (2013))

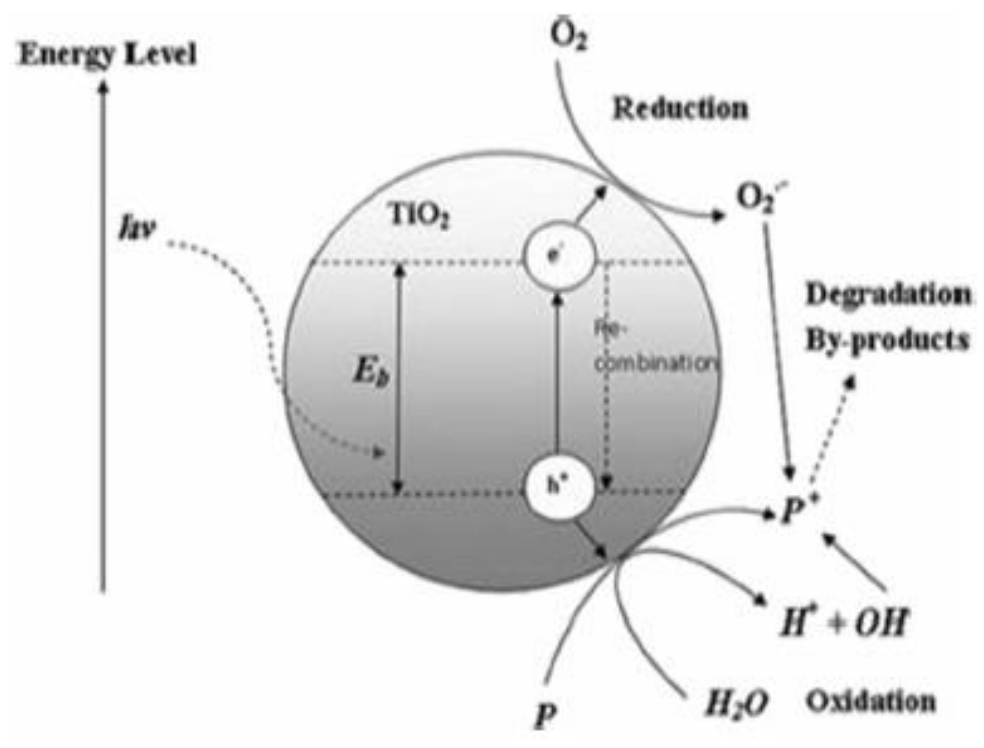

The application of $\mathrm{TiO}_{2}$ as photocatalyst was started by Fujishima and Honda in 1972 (Fujishima et al. 2000; Kondo et al. 2008). These authors used a photo-electrochemical cell made up of a rutile titania anode and inert cathode to split water into hydrogen and oxygen. This achievement served as a turning point in the history of heterogeneous photocatalysis. Ever since then, scientists across the globe have conducted far-reaching research trying to understand the fundamental processes and see how to improve the photocatalytic efficiency of $\mathrm{TiO}_{2}$. Nano-TiO 2 stands as the most widely investigated heterogeneous photocatalysts in comparison to others due to its unique advantages such as biological and chemical resistance, safety, low price and affordability, environmental friendliness, and ease of use over other oxides (Chanathaworn et al. 2012; Dolat et al. 2012). The technology can be operated at ambient temperature and pressure, and has been demonstrated to be very effective to treat pollutants both in gas and in liquid phase, elimination of intermediate dead products without necessarily produces sludge, and, above all, low cost of operations. This review will focus on the heterogeneous semiconductor titanium (IV) oxide. Far-reaching investigations have been conducted either on the use of titania photocatalysts or its immobilized forms to destroy organic compounds (Malato et al. 2009). Girginov et al. (2012) demonstrated the photocatalytic efficiency of Ag-doped $\mathrm{TiO}_{2}$ for methyl orange degradation and found that immobilization of $\mathrm{Ag}$ onto $\mathrm{TiO}_{2}$ nanoparticles increased the photocatalytic activity in contrast to the standard titania. Silver acted as an electron trapper which reduces the electron- hole recombination rate and subsequent increase in absorption coefficient. In a related development, Naik et al. 2012) found that the crystalline phase and crystalline nanoform of $\mathrm{TiO}_{2}, \mathrm{Ag}-\mathrm{TiO}_{2}$, and $\mathrm{TiO}_{2}-\mathrm{SBA}-15$ nanocomposites remove and degrade methyl orange according to calcination temperature. The findings revealed that Ag-doped $\mathrm{TiO}_{2}$ nanoparticles had high photocatalytic activity than undoped $\mathrm{TiO}_{2}$. In the same vein, Behnajady et al. (2008) applied the liquid impregnation (LI) and photodeposition (PD) methods to synthesize $\mathrm{Ag}$-doped $\mathrm{TiO}_{2}$ nanoparticles for the degradation of C.I. Acid Red 88 (AR88). The results of both methods indicated that silver 
immobilized upon $\mathrm{TiO}_{2}$ was faster at degrading AR88 photocatalytically than undoped $\mathrm{TiO}_{2}$. The difference was attributed to the ability of silver to trap electrons. However, the AR88 decomposition with Ag-doped titania synthesized by PD was higher than that deposited with LI method. Nainani et al. (2012) reported that $\mathrm{Ag}-\mathrm{TiO}_{2}$ was more active for the mineralization of methylene blue than undoped $\mathrm{TiO}_{2}$. It was also discovered that $\mathrm{Ag}$ loading was responsible for the phase change of anatase to rutile. Also, Li et al. (2011) observed that as the amount of Ag-loading increased; there was a corresponding red shifting of $\mathrm{Ag}-\mathrm{TiO}_{2}$ absorption edge resulting in the decrease band gap energy. The photocatalytic activity of $\mathrm{Ag}-\mathrm{TiO}_{2}$ increased with the molar ratio of $\mathrm{Ag}$-doped from o to $0.8 \%$, but a decrease in the photocatalytic activity was discovered even despite further increase of the molar ratio of $\mathrm{Ag}$ to $2.0 \%$. The visible photoactivity of the nanocomposites was plausibly due to Ag deposits that acted as electron trapper and promoted methylene blue adsorption. Alrousan et al. (2009) studied the photocatalytic inactivation of Escherichia coli in surface water using immobilized nanoparticle $\mathrm{TiO}_{2}$ film. The authors revealed that the photocatalytic inactivation of $E$. coli was considerably lower in surface water than in distilled water. The presence of anions such as nitrate and sulphate spiked into distilled water could have been responsible for the decrease in the photocatalytic disinfection rate. However, the photocatalytic inactivation of $E$. coli is not dependent on the initial $\mathrm{pH}$ of the surface water. On the contrary, humic acid in surface water reduces the photocatalytic disinfection rate. Yang et al. (2006) demonstrated the synthesis of anatase $\mathrm{TiO}_{2}$ nanoparticles for the degradation of methyl orange using a solgel method. The effects of $\mathrm{H}_{2} \mathrm{O}_{2}$ addition, $\mathrm{pH}, \mathrm{TiO}_{2}$ phase composition, and the recycled $\mathrm{TiO}_{2}$ on the photocatalytic degradation of methyl orange $(\mathrm{MeO})$ in $\mathrm{TiO}_{2}$ suspensions under UV illumination were monitored. The authors revealed that low $\mathrm{pH}$ value, and $\mathrm{H}_{2} \mathrm{O}_{2} / \mathrm{TiO}_{2}$ addition were responsible for the photocatalytic oxidation of the $\mathrm{MeO}$ solution. The photodegradation rate decreased with an increase in $\mathrm{pH}$ value of the solution and varied with different amounts of $\mathrm{H}_{2} \mathrm{O}_{2}$. The obtained pure anatase $\mathrm{TiO}_{2}$ showed better photocatalytic activity towards $\mathrm{MeO}$ decolorization than biphase $\mathrm{TiO}_{2}$. Chen et al. (2007) employed a nanosized $\mathrm{TiO}_{2}$ powder to degrade dimethoate. It was observed that there was no correlation between the dimethoate and $\mathrm{TiO}_{2}$ concentration increment, and, as such, low degradation of the pollutants was observed. On the other hand, $\mathrm{H}_{2} \mathrm{O}_{2} / \mathrm{K}_{2} \mathrm{~S}_{2} \mathrm{O}_{8}$ incorporation with photocatalysis followed by sonication enhanced the decomposition efficiency. Sano et al. (2011) found that application of multiwalled carbon nanotubes in a wetted wall corona discharge reactor enhanced phenol degradation in water. The authors further observed an increase in the anode surface area as well as incorporation of cobalt nanoparticle onto multiwalled carbon nanotubes improved the decomposition of phenol and TOC value. The application of heterogeneous photocatalysis towards degradation of pollutant indicated that pollutant removal depends largely on parameters such as solution $\mathrm{pH}$, initial organic pollutants type and concentration, catalyst loading, dissolved oxygen, light wavelength and intensity quantity of reactive oxygen species, temperature, absence of interfering ions, and ionic profile of the polluted water. These parameters either raise or reduce the reaction rate depending on 
the pollutants' structural complexity and hydrophobic tendencies. Details on the influence of the above-mentioned parameters on the photocatalytic activity of $\mathrm{TiO}_{2}$ have been comprehensively reviewed by Chong et al. (2010). Despite the vast potentials associated with advanced oxidation techniques as a polishing step to eliminate refractory nonbiodegradable organic pollutants from wastewater, there still exist challenges and shortcomings which researchers are currently trying to address. One of such is the slow photocatalytic activity kinetics of $\mathrm{TiO}_{2}$ in the visible region caused by high band gap energy and short-lived nature of electron-hole carriers linked to lower photon quantum efficiency. Most importantly, difficulty in light penetration of a solution containing suspended titania nanocomposites, filtration of the suspended $\mathrm{TiO}_{2}$ nanoparticles after the treatment process, which is time consuming and expensive. Other technical challenge includes the agglomeration of nanoparticles, designing of a photocatalytic reactor, and difficulties in the reactor optimization. Several studies have been focused on addressing some of the challenges of heterogenous photocatalysis, among which is the doping/immobilization of nonmetal or metal onto the semiconductor catalyst (Zhu et al. 2008; Tryba et al. 2009; Homem and Santos 2011). Plasmonic metals (silver and gold) are often applied to trap the charges on $\mathrm{TiO}_{2}$, thus enhancing the responsiveness of the catalyst to visible light. The immobilization of the $\mathrm{TiO}_{2}$ upon different support materials such as glass, stainless steel mesh, ceramics, polymers, activated carbon, and zeolites is another step to avoid postseparation problems after treatment but still needs further study. The conclusions of various studies have shown clearly that doping of heterogeneous photocatalyst with either metal or nonmetals enhanced the photocatalytic activity and improve the decomposition rate of organic pollutants. Thus, heterogeneous photocatalysts developed on a support could be integrated with either electrohydraulic discharge systems or ultrasonic irradiation techniques so as to accelerate the degradation rate of recalcitrant toxic pollutants present while maximizing cost and the same time reducing the reaction time.

\subsection{Ultrasonic Treatment}

Ultrasonic irradiation, otherwise known as sonolysis or sonochemistry, represents another promising AOTs used for degradation of organic pollutants without adding chemicals. According to Chowdhury and Viraraghavan (2009), ultrasonic irradiation may be categorized into high frequency $(2-10 \mathrm{MHz})$ and low frequency ultrasound $(20-100 \mathrm{kHz})$. The ultrasonic reactions occur as a result of high irradiation sound on water at a frequency range of $20 \mathrm{kHz}$ to $1 \mathrm{MHz}$ which produce cavitation bubbles and explosions. This cavitation may be ultrasonic and hydrodynamic in nature. The collapsing of the bubbles give rise to a pyrolysis reaction occurring at high temperature and pressure in the range of $3,000-5000{ }^{\circ} \mathrm{K}$ and 500-10,000 atm, respectively (Patil and Pandit 2007; Doosti et al. 2012). This is subsequently followed by water dissociation into hydroxyl radicals, while oxygen eventual split and attack the target organic pollutants (Entezari et al. 2006; Mahvi $2009 \mathrm{H}_{2} \mathrm{O} \rightarrow \mathrm{O}_{2}$ $\rightarrow 2 \mathrm{O} 2$

The generated hydrogen radical sometime react further oxygen in the system to form peroxide radicals, $\left(\mathrm{HO}_{2}{ }^{\circ}\right)$ and hydrogen peroxide $\left(\mathrm{H}_{2} \mathrm{O}_{2}\right)$. The detailed reaction

\section{http://repository.uwc.ac.za}


mechanism of the sonochemical process is shown in Fig. 4. Over the years, ultrasonic irradiation treatment, either alone or in a combined form, has been applied to remove organic pollutants from wastewater (Lin and Ma 2000; Stavarache et al. 2002; Neppolian et al. 2004; Emery et al. 2003; Jiang and Waite 2003; Adewuyi 2005; Augugliaro et al. 2006; Chowdhury and Viraraghavan 2009; Mahamuni and Adewuyi 2010; Seguraa et al. 2012; Weng et al. 2013). Despite its potential capability, recent studies indicated that ultrasonic irradiation is not commonly used industrially compared to other AOTs (Klavarioti et al. 2009; Doosti et al. 2012). This is due to the difficulty in the scaling up for commercial use. This treatment technology is more advantageous in terms of operational simplicity, cleanliness, than other known technologies such as photolysis, Fenton and photo-Fenton process, electrohydraulic discharge system, etc. The process is also sludge free, safe, and clear with no generation of secondary pollutants and better energy conservation (Chowdhury and Viraraghavan 2009). Other advantage especially over photolysis or photocatalysis lies in its ability to penetrate cloudy water. Ultrasonic irradiation can decomposes poorly soluble and volatile organic pollutants present in wastewater having high suspended solids or turbidity value causing interference (Mahvi 2009). At the moment, this technology is only viable at a small scale. Ultrasonic irradiation technique is quite efficient for degradation of recalcitrant-persistent organic pollutants; however, complete mineralization was not be achieved in most of the cases. This might be due to higher polarity of the organic compound, low availability of $\mathrm{OH}$ radical, or lack of dissipated power (Chowdhury and Viraraghavan 2009). For instance, Guo and Feng (2009) utilized ultrasonic irradiation at low frequency to eliminate Bisphenol-A in aqueous solution. The decomposition rate was found to depend on the ozone dosage and ultrasonic intensity. The degradation rate increases with increase in ultrasonic intensity. The treatment was accompanied with formation of six secondary by-products such as phenol, 4-isopropenylphenol, hydroquinone, 4 hydroxyacetophenone, 2-hydroxypropionic acid, and glycerol. Geng and Thagard (2013) found that applied pressure significantly influenced the ultrasonic degradation of Rhodamine B. Higher decomposition of the pollutant was achieved at high pressure.

To solve these problems, sonolysis process can be coupled with other advanced oxidation processes. Integration of ultrasonic treatment with other AOTs will enhance the degradation efficiency. The combination of ultrasound with photocatalysis (sonophotocatalysis) has been explored in the literature (Augugliaro et al. 2006). The simultaneous use of both techniques for degradation of organic is considered more economically viable and highly effective than using sequential ultra-sonic irradiation alone. And the overall decomposition rate in most cases was found to be equal to the sum of the individual rates for photocatalysis and ultrasonic irradiation. Heterogeneous photocatalysis and sonolysis can degrade priority organic pollutants in wastewater by the active species especially $\mathrm{HO}^{\circ}$ radicals. Conversely, photocatalytic process involves electron transfer from the organic compounds onto semiconductor oxide surface while ultrasonic irradiation may decompose pollutants via pyrolysis reaction. For the ultrasonic treatment, the production of hydroxyl radical is through cavitation activity involving bubbles collapsing at higher temperature and pressure.

\section{http://repository.uwc.ac.za}




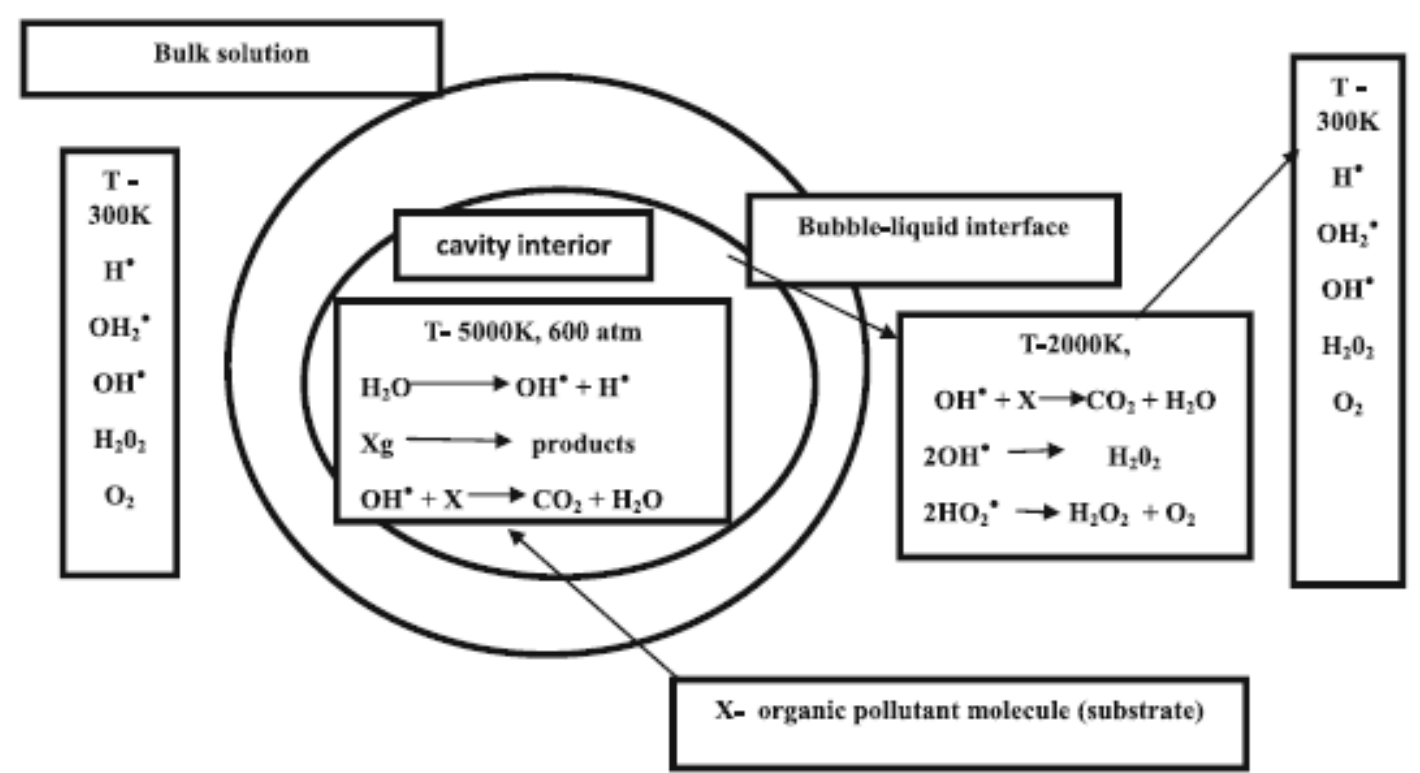

Fig. 4 The reaction mechanism of the bubble cavity (adapted from Adewuyi (2001), Chowdhury and Viraraghavan (2009) and Joseph et al. (2009)

The role played by reactive species such as hydroxyl radical, hydrogen peroxide, and ozone, have been subject of extensive investigations in the recent time. Some of the studies where combined technology was used are reviewed as follows. Siddique et al. (2014) coupled ultrasound with heterogeneous catalysis to degrade reactive dye 19. It was found that the degree of degradation increased by decreasing $\mathrm{pH}$, initial dye concentration, and increasing catalysts loading and ultrasonic power with respect to photocatalytic and sonophotocatalytic. In fact, it was reported that after 120 min of treatment, 73, 35, and $12 \%$ dye degradation occurred with sonophotocatalysis, photocatalysis, and sonolysis processes, respectively. Thus, the combined technique was more effective than the respective individual processes due to the accelerated formation of active species caused by ultrasound-cavitation activity. Bokhale et al. (2014) utilized sonocatalytic and sonophotocatalytic treatment process to destroy and decompose aqueous solution containing Rhodamine 6G (Rh 6G). The influence of cupric oxide and titanium dioxide as a solid catalyst were further investigated. It was reported that $52.2 \%$ and $51.2 \%$ degradation rate was obtained at the optimum loading of cupric oxide and titanium dioxide respectively. The introduction of radical scavengers such as methanol and n-butanol negatively affect the degradation efficiency. Thus, combined approach such as ultrasonic irradiation and heterogeneous photocatalysis give overall higher degradation rate of 63.3 $\%$ than individual technology such as ultrasonic irradiation and photolysis.Ultrasonic airlift reactor and ozonation were combined to degrade dimethoate in solution. The influence of ozone, $\mathrm{pH}$, ultrasonic intensity, as well as temperature was examined. The authors found that the rate of degradation of dimethoate was short with the introduction of ozone. Ozone acted as an oxidant and enhanced the reaction rate (Liu et al. 2008). The authors suggested that an integrated system is more beneficial and economical in the removal of pesticide from wastewater than single-treatment process. Xu et al. (2005) combined sonolysis/ozonolysis process to degrade $p$-nitrophenol in water. When the

\section{http://repository.uwc.ac.za}


system such as sonolysis and ozonolysis were used individually, the mineralization and de-composition rate were not significant. However, when both system were combined, more hydroxyl radical and hydrogen peroxide were produced which perhaps enhanced the removal rate $(116 \%)$ than individual process. Thus, there was a synergistic effect when ozonation with ultrasonic irradiation were coupled to treat $p$-nitrophenol. The combination of sonolysis with ozonolysis seems effective for decomposing the pollutants due to increase mass transfer of ozone, excessive hydroxyl radical, and other secondary species such as $\mathrm{O}^{2}{ }^{-}$and $\mathrm{HO}^{2}{ }^{*}$. The sources of hydroxyl radicals were ascribed to sonochemical degradation of water and thermolytic breakdown of ozone. Wang et al. (2009) demonstrated that combination of ultrasonic cavitation and hydrogen peroxide remove rhodamine $\mathrm{B}$ easily from aqueous solution. This is due to a synergistic effect between cavitation and hydrogen peroxide. An increase in hydrogen peroxide dosage and pressure were observed to enhance the degradation efficiency, although other parameters studied such as $\mathrm{pH}$, temperature, and initial dye concentration affects the mineralization of rhodamine B retrogressively. Guo et al. (2008) studied the effects of additives on the sonolytic degradation of 2,4-dinitrophenol (DNP) in aqueous solution. With ultrasonic irradiation alone, only $14 \%$ degradation was observed after $4 \mathrm{~h}$ of treatment. Even when hydrogen peroxide was added, there was no significant increase in the degradation rate. Only $4 \%$ increase. Eighty-seven percent decomposition rate was obtained when $\mathrm{CuO} / \mathrm{H}_{2} \mathrm{O}_{2}$ were coupled together. Furthermore, combination of $\mathrm{US} / \mathrm{CuO} / \mathrm{H}_{2} \mathrm{O}_{2}$ enhanced the degradation rate by $93 \%$. When air was introduced into the combined system, the rate of degradation was further enhanced by $96 \%$. Thus, $\mathrm{US} / \mathrm{CuO} / \mathrm{H}_{2} \mathrm{O}_{2} /$ air system was effective for the degradation of 2,4-DNP from aqueous solution. This was attributed to increase yield of $\mathrm{OH}$ radicals, which perhaps played a dominant role in DNP ultrasonic removal. Katsumata et al. (2011) combined ultrasound/ferrioxalate/UV irradiation to degrade fenitrothion in the presence of $\mathrm{Fe}$ (III) and oxalate. The decomposition rate was dependent on Fe(III) and oxalate concentration. The combined system destroyed $10 \mathrm{mg} / \mathrm{L}$ solution of fenitrothion within $30 \mathrm{~min}$ at $\mathrm{pH}$ 6 , with a consequent reduction in total organic carbon. Forty percent degradation was achieved with ultrasonic alone, $87 \%$ decomposition was obtained with ferrioxalate/UV, while $99 \%$ decomposition was recorded with the combination of ultrasound/ferrioxalate/UV technique. Thus, integrated process such as US/ferrioxalate/UV process was fastest in all which could be employed to treat wastewater containing other pesticides and endocrinedisrupting chemicals. Zhang et al. (2006) utilized the combination of ultrasonic irradiation and ozonation to decompose methylene orange. The authors concluded that there was synergy between the two combined techniques. The synergistic effect became prominent due to the increase in the system temperature caused by the ultrasonic irradiation. The degradation rate was dependent on increasing ultrasonic power, flow rate, and ozone concentration. However, solution $\mathrm{pH}$ did not have a significant effect on the decolorization rate; at the same time, ultrasound had no effect on the rate of decolorization. The rate constant $K_{1}\left(0.3 \mathrm{~min}^{-1}\right)$ of the combined US/O 3 system was higher than ozonation alone $\left(0.27 \mathrm{~min}^{-1}\right)$. 
Wang et al. (2007) combined photocatalysis and sonophotocatalysis to remove methyl parathion from aqueous solution. The authors showed that the obtained decomposition rate of methyl parathion by sonocatalytic process with microsized anatase $\mathrm{TiO}_{2}$ powder was better than nanosized rutile $\mathrm{TiO}_{2}$ powder. The rate of degradation was established to depend on the investigated parameters. Shimizu et al. (2007) studied the influence of photocatalysis, ultrasonic irradiation, and hydrogen peroxide on the removal of methylene blue from aqueous solution. About $22 \%$ reduction in the methylene blue concentration was observed without adding $\mathrm{H}_{2} \mathrm{O}_{2}$, subsequently with the addition of $\mathrm{H}_{2} \mathrm{O}_{2}$ to methylene blue containing $\mathrm{TiO}_{2}, 85 \%$ reduction was noticed. The decomposition rate was found to depend on $\mathrm{TiO}_{2}$ dose as well as its specific surface area. However, no reasonable degradation was noticed when $\mathrm{H}_{2} \mathrm{O}_{2}$ was added to methylene blue solution containing $\mathrm{Al}_{2} \mathrm{O}_{3}$. Thus, the combined ultrasonic irradiation with photocatalyst improved the degradation of the pollutant. This was ascribed to greater yield of hydroxyl radicals. Wang et al. (2008a) found that the rate of degradation of reactive brilliant red K-BP was dependent on the reactive brilliant red K-BP

concentration; the temperature was considerably enhanced by the addition of $\mathrm{Fe}^{2+} \mathrm{NaCl}$ or Fenton reagent. Hamdaoui and Naffrechoux (2008) revealed that process coupling such as the ultrasonic irradiation with photolysis resulted in an increased mineralization rate compared to the individual operating technique at the same conditions. The degradation rate of 4-chlorophenol (4-CP) was small compared to when photosonochemical technique was combined. This means there was a greater synergistic effect among the three oxidative processes such as direct photochemical action, high-frequency sonochemistry, and reaction with ozone produced by UV irradiation of air. In another study, Chandi et al. (2009) combined ultrasonic irradiation with hydrogen peroxide, ozone, zero valent copper (ZVC), and iron (ZVI) nanoparticles to remove phenol from aqueous solution. With ultrasonic irradiation alone at $20 \mathrm{kHz}$, no phenol was removed even after 45 min, although $39 \%$ TOC mineralization was observed. Even with the introduction of ZVC, the TOC removal was found to be negligible; only $10 \%$ and $26 \%$ removal and degradation rate was achieved. Addition of ZVC further enhanced phenol removal to $83 \%$; however, the maximum TOC mineralization achieved was only $26 \%$ within 25 min. The combination of $\mathrm{US} / \mathrm{O}_{3}$ did not produce satisfactory result. This is so because ozone does not favor high carbon mineralization due to insufficient radical formation via oxygen-transfer from ozone lead pathways. With the US/ZVI/ $\mathrm{H}_{2} \mathrm{O}_{2}$ system, high TOC mineralization (35 \%) with a corresponding phenol removal of $98 \%$ was observed. When US/with US/air/ZVI/ $\mathrm{H}_{2} \mathrm{O}_{2}$ was subjected to $300 \mathrm{kHz}$, complete phenol removal (100 \%) and $37 \%$ TOC mineralization was achieved within $20 \mathrm{~min}$. US/Air/ZVI/ $\mathrm{H}_{2} \mathrm{O}_{2}$ integrated system was found to be most efficient among the different combinations due to increase production rate of hydroxyl radical caused by cavitational intensity and the dissociation effect of hydrogen peroxide. Hartmann et al. (2008) studied the impact of combined process such as sonolysis with $\mathrm{TiO}_{2}, \mathrm{SiO}_{2}, \mathrm{SnO}_{2}$, or titanosilicate on the removal of diclofenac from aqueous solution. Among the studied catalysts, $\mathrm{TiO}_{2}$ significantly reduced concentration of diclofenac by $84 \%$ within 30 min of irradiation time. The incorporation of catalyst with sonolytic process improves the degradation rate. Wang 
et al. (2008) investigated the removal of methyl orange using sonophotocatalytic process. The influence of solution $\mathrm{pH}, \mathrm{Ag} / \mathrm{TiO}_{2}$ dosage, effect of irradiation time, initial methyl orange concentration, variation of ultrasonic power, and frequency were evaluated. The degradation ratio of methyl orange was found to increase as ultrasonic power increased. Hydroxyl radical detection by mannitol and dimethyl sulfoxide indicated that the radical played a prominent role in the decomposition of methyl orange. Wu et al. (2008) combined irradiation with microwave and ultrasound with or without peroxide addition to degrade phenol in water. The individual process failed to effectively degrade phenol. The incorporate of hydrogen peroxide improve the degradation rate. Anandan and Ashokkumar (2009) investigated the removal of nonylphenol ethoxylate (NPE) from aqueous solution using photocatalysis and sonophotocatalysis. It was observed that $\mathrm{TiO}_{2}$ nanoparticle was effective for the removal of the toxicants. There was no synergy between sonolysis and photocatalysis. This might be due to the failure in the identification and quantification of the degraded products during the simultaneous treatment by photolight and ultrasound. Mishra and Gogate, (2011) investigated the degradation of p-nitrophenol by sonophotocatalytic technique at low frequency wave of $25 \mathrm{kHz}$ with a corresponding dissipated power of $1 \mathrm{~kW}$. The process integration such as sonophotocatalysis process with the optimum concentration of hydrogen peroxide resulted to $94.6 \%$ mineralization rate of p-nitrophenol. It was also observed that Fenton process played a key role by improving the rate of degradation of p-nitrophenol. Madhavan et al. (2010a, b) used sonolytic, photocatalytic, and sonophotocatalytic process to remove ibuprofen from water. The impact of UV irradiation on the degradation of IBP was not felt. However, with the incorporation of ultrasonic irradiation, about $18 \%$ decomposition rate occurred within $10 \mathrm{~min}$. With $10 \mathrm{~min}$ of treatment with sonocatalytic conditions, $23 \%$ degradation rate was observed. Further increase in the degradation rate precisely $5 \%$ was noticed in the presence of $\mathrm{TiO}_{2}$ particles during sonolysis. This increase was due to cavitation activity. However, with photocatalytic degradation alone, about $61 \%$ degradation was achieved in $15 \mathrm{~min}$; when ultrasonic irradiation, photocatalyst, and UV were combined (sonophotocatalysis), about $85 \%$ of ibuprofen decomposed with $15 \mathrm{~min}$. Twenty-four percent increment in the degradation under the same processing time suggests that the hydroxyl radicals formed by both the advanced oxidation processes, viz., photocatalysis and sonolysis are involved in the sonophotocatalytic degradation of IBP. In addition, Rasheed et al. (2011) combined ultrasonic irradiation and zero-valent iron particles to treat petroleum refinery wastewater and close to $40 \%$ COD reduction was achieved within 1 hour of treatment with ultrasonic irradiation alone. However, with addition of zero-valent iron, further and considerable reduction in the COD level over certain time was observed. This was attributed to the hemolytic cleavage of water molecules which increase the concentration of hydroxyl radical responsible for the degradation of the pollutant. Wang et al. (2011) combined powdered photocatalysis $\left(\mathrm{TiO}_{2}\right)$ and jet cavitation to remove C.I reactive red 2. The combined process improved the dye degradation rate due to a synergistic effect and more reactive species being formed. The coupled system was more efficient at lower concentration of $\mathrm{TiO}_{2}$ than at higher $\mathrm{TiO}_{2}$ concentration. Anju et al. (2012) studied the removal of phenol from water by combined ultrasound irradiation and powdered heterogeneous photocatalysis $\left(\mathrm{ZnO}, \mathrm{TiO}_{2}\right.$, and $\left.\mathrm{ZnO}-\mathrm{TiO}_{2}\right)$. The degradation of the phenol was found to depend on the 
catalyst loading, irradiation time, initial $\mathrm{pH}$, and concentration of the substrate. The combined $\mathrm{ZnO}-\mathrm{TiO}_{2}$ degraded phenol more than the sum of individual oxides, thus establishing a synergistic effect. Inoue et al. (2008) reported the sonochemical degradation of bisphenol-A in aqueous solution. The rate of degradation increases with increasing in the ultrasonic intensities. With ultrasonic irradiation alone, the TOC value was $20.2 \%$ with a corresponding ultrasonic intensity of $12.9 \mathrm{~kW} / \mathrm{m}^{2}$ after $10 \mathrm{~h}$. However, when combined with Fenton reagent, the TOC value further reduced by $30 \%$ without reducing the time necessary to degrade bisphenol-A. Thus, combination of Fenton and ultrasonic irradiation process significantly enhanced the mineralization rate. Madhavan et al. (2010a, b) studied the degradation and mineralization of orange-G (OG) by combination of ultrasonic irradiation and heterogeneous photocatalyst. The effects of parameters (such as the concentration of the dye and solution) and $\mathrm{pH}$ on the degradation efficiency were evaluated. The sonolytic decomposition of orange-G was higher at lower $\mathrm{pH}(5.8)$ than at high $\mathrm{pH}$ (12). But, alkaline $\mathrm{pH}$ preferentially favored the photodegradation of the pollutant. The individual process such as sonolysis and photocatalyst achieved 43 and $58 \%$ decomposition after $75 \mathrm{~min}$, respectively. However, when process US and UV were coupled (sonophotocatalysis), a significant improvement in the degradation ( $85 \%$ in $75 \mathrm{~min}$ ) of the pollutant was observed, indicating that hydroxyl radicals produced via the excitation of $\mathrm{TiO}_{2}$ and water sonolysis route. Jamalluddin and Abdullah (2011) combined $\mathrm{Fe}(\mathrm{III}) / \mathrm{TiO}_{2}$ catalyst and ultrasonic irradiation to degrade reactive blue 4 (RB4) in water. Without the addition of the catalysts, the elimination rate of RB4 was just about $12 \%$ within 60 min of treatment. The lower rate linked to the short-lived nature of $\mathrm{OH}$ radicals, this perhaps reduces the possibility for the dye compound to be attacked by the radicals. However, the combination of $0.4 \mathrm{~mol} \%$ of $\mathrm{Fe}(\mathrm{III}) / \mathrm{TiO}_{2}$ with ultrasonic irradiation significantly enhanced the removal of $\mathrm{RB} 4$ from the aqueous solution by $82 \%$. The increase in overall process efficiency according to the authors was due to the simultaneous coincidence of homogeneous and heterogeneous catalyst which peradventure increases the generated free hydroxyl radicals. LastreAcosta et al. (2014) investigated the degradation of sulfadiazine in aqueous solution using high frequency ultrasonic irradiation greater than $100 \mathrm{kHz}$. The authors reported higher sulfadiazine removal with lowest operating frequency, lower $\mathrm{pH}$ and higher dissipated power. On the contrary, addition of hydrogen peroxide negatively affect the degradation rate while incorporation of Fenton reagent significantly improve the removal rate of sulfadiazine. Thus sono-Fenton process seems to be a novel technology for the removal of sulfadiazine from water than sonolysis alone. Patil et al. (2014) have applied single sonochemical reactor and combined ultrasound treatment strategies to degrade wastewater stream containing imidacloprid. The rate of degradation was $92.7 \%$ with combination of ultrasound and hydrogen peroxide. In the same vein, $96.5 \%$ decomposition rate of the target pollutant was obtained when ultrasound irradiation was coupled with advanced Fenton process. The obtained results of $79 \%$ TOC removal with the combination of ultrasound, ultraviolet light and hydrogen peroxide seems to be the best treatment for the removal of the target compound. Thus, the process integration involving ultrasonic irradiation with different advanced oxidation can successfully destroy imidacloprid in wastewater. Other synergistic effects of sonolysis with photocatalysis are presented in Table 3. Whatever success recorded by ultrasonic irradiation, the applications of ultrasonic irradiation are not without some shortcomings such as high consumption of energy,

\section{http://repository.uwc.ac.za}


long time treatment of contaminants, difficult to operate at low frequency, non-uniform distribution of cavitation, and difficulty in scaling up. Generally, it was discovered that ultrasonic irradiation can perfectly combined with other AOTs such as heterogeneous photocatalysis, hydrogen peroxide, ozonation, zero valent iron, etc. and achieve greater results. Ultrasound can be integrated with other AOTs to further improve the process performance and efficiency (Table 3). Most review papers were still at the laboratory level, which will be somehow difficult to implement directly into full-scale commercialization. Further research is required regarding degradation kinetics, process reactor design, and full-scale commercialization for environmental application.

\subsection{Combination of Advanced Oxidation Technology with Biological Treatment}

Different wastewater treatment techniques such as biological, chemical oxidation, and advanced chemical oxidation have been extensively reviewed in the literature (Scott and Ollis 1995; Oller et al. 2011). However, the most critical challenge is the selection of an appropriate treatment process capable of mineralizing the target pollutant. The selection of one over the other depends on factors such as economic cost, treatment flexibility, treated water quality, decontamination efficiency, etc. 
Table 3 Synergetic effect of ultrasound with sonophotocatalytic process

\begin{tabular}{|c|c|c|c|c|}
\hline $\begin{array}{l}\text { Contaminants } \\
\text { degraded }\end{array}$ & Concentration & Chemical oxidation scheme & Comments/discussion & References \\
\hline Acid orange 7 & $1.43 \times 10^{-4} \mathrm{M}$ & $\begin{array}{l}\mathrm{He}-\mathrm{Ne} \text { laser }\left(632 \mathrm{~nm}, 100 \mathrm{~mW} / \mathrm{mm}^{2}\right) \text {, } \\
2 \text { transducer-type sonicator } \\
(f=20 \mathrm{kHz} \text { and } 1 \mathrm{MHz}, i=40 \mathrm{~W})\end{array}$ & $\begin{array}{l}\text { Combining visible light and } \\
\text { sonication provided the } \\
\text { synergistic degradation effect } \\
\text { which can be explained as the } \\
\text { effect to the reduction of the } \\
\text { band gap energy of the dye } \\
\text { (from absorption of photon } \\
\text { energy oflight), induced by high } \\
\text { temperature and high pressure } \\
\text { via the bubble collapse under the } \\
\text { sonication process }\end{array}$ & $\begin{array}{r}\text { Ma et al. } \\
\text { (2006) }\end{array}$ \\
\hline Acid orange 8 & $4 \times 10^{-5} \mathrm{M}$ & $\begin{array}{l}\text { (Degussa } \mathrm{P} 25) \mathrm{TiO}_{2} \text { and } \mathrm{ZnO} \\
(0.1 \mathrm{~g} / \mathrm{L}), \mathrm{UV}-\mathrm{A} \text {, Iron halogenide } \\
\text { lamp }(315-400 \mathrm{~nm}, 250 \mathrm{~W}) \text {, hom- } \\
\text { type sonicator }(f=20 \mathrm{kHz}, i=20 \mathrm{~W})\end{array}$ & $\begin{array}{l}\text { Sonication of the aqueous system } \\
\text { produced } \mathrm{H} 2 \mathrm{O} 2 \text { which in tum } \\
\text { generated }(\mathrm{OH}) \text { during } \mathrm{SPC} \text { re- } \\
\text { action, thus enhancing the deg- } \\
\text { radation process via a synergis- } \\
\text { tic effect }\end{array}$ & Selli (2002) \\
\hline Reactive black 5 & $20-120 \mathrm{mg} / \mathrm{L}$ & $\begin{array}{l}\text { (Anatase-Aldrich, Hombikat UV-100, } \\
\text { Degussa P25, Tronox AK1 } \\
\text { Millennium PC 500), } \mathrm{TiO}_{2} \\
(0.05-1 \mathrm{~g} / \mathrm{L}) \text {, UV-A }(9 \mathrm{~W}, 350- \\
400 \mathrm{~nm}), \text { hom-type sonicator } \\
(f=80 \mathrm{kHz}, i=135 \mathrm{~W}), \mathrm{H}_{2} \mathrm{O}_{2} \\
(0.01 \mathrm{M}) \mathrm{pH}(2.6-9)\end{array}$ & $\begin{array}{l}\text { Addition of } \mathrm{H} 2 \mathrm{O} 2 \text { hindered } \\
\text { degradation due to scavenging } \\
\text { of photogenerated holes and } \\
\mathrm{OH} \cdot \text { complete decolorization } \\
\text { was achieved after } \mathrm{SPC} \\
\text { treatment of } 60 \mathrm{mg} / \mathrm{L} \text { dye, } \\
0.25 \mathrm{mg} / \mathrm{L} \text { catalyst ambient } \\
\text { pH } 5.8 \text { with } \mathrm{O} 2 \text { sparging }\end{array}$ & $\begin{array}{l}\text { Kritikos } \\
\quad \text { et al. } \\
(2007)\end{array}$ \\
\hline Phenol & $0.5-5 \mathrm{mmol} / \mathrm{dm}^{3}$ & $\begin{array}{l}\mathrm{TiO}_{2} / \text { activated carbon sol gel catalyst } \\
(3-4 \mathrm{~g} / \mathrm{dm} 3) \text {, hom-type sonicator } \\
(f=20 \mathrm{kHz}, i=75 \mathrm{~W})\end{array}$ & $\begin{array}{l}\text { Under sonication, the amount of } \\
\text { catalyst is proportionate to the } \\
\text { degradation rate of the phenol }\end{array}$ & $\begin{array}{l}\text { Kubo et al. } \\
\quad(2007)\end{array}$ \\
\hline Methyl orange & $32 \mathrm{mg} / \mathrm{L}$ & $\begin{array}{l}\left.\text { (Degussa } \mathrm{P} 25 \text {, Yili } \mathrm{TiO}_{2}, \mathrm{Ag} / \mathrm{TiO}_{2}\right) \\
\mathrm{TiO}_{2}(36 \mathrm{mg} / \mathrm{L}), \text { Xenon lamp } \\
(800 \mathrm{~W}, 688-599 \mathrm{~nm}) \text {, transducer- } \\
\text { type sonicator }(f=40 \mathrm{kHz} \\
i=180 \mathrm{~W})\end{array}$ & $\begin{array}{l}\text { Synergistic effect between } \\
\text { sonolysis and photocatalysis } \\
\text { were demonstrated in the } \\
\text { complete decomposition of } \\
\text { methyl orange. The degradation } \\
\text { ratio of methyl orange was } \\
\text { proportional to the increased in } \\
\text { sonication energy }\end{array}$ & $\begin{array}{c}\text { Wang et al. } \\
\text { (2008) }\end{array}$ \\
\hline $\begin{array}{l}\text { 2-Chlorophenol, acid } \\
\text { orange } 8 \text { and acid } \\
\text { red } 1\end{array}$ & $5 \times 10^{-4} \mathrm{M}, 2-7 \times 10-\mathrm{M}$ & $\begin{array}{l}\text { (Degussa } \mathrm{P} 25) \mathrm{TiO}_{2}(0.1 \mathrm{~g} / \mathrm{L}), \mathrm{UV}-\mathrm{A} \text {, } \\
\text { Iron alongenide lamp }(250 \mathrm{~W} \text {, } \\
315-400 \mathrm{~nm}), \text { hom-type sonicator } \\
(f=20 \mathrm{kHz}, i=15 \mathrm{~W})\end{array}$ & $\begin{array}{l}\text { Sonication promoted the rate of } \\
\text { photocatalytic degradation by } \\
\text { promoting the deaggregation of } \\
\text { the photocatalyst and by } \\
\text { inducing the desorption of } \\
\text { organic substrates as well as the } \\
\text { degradation of the intermediates } \\
\text { from the photocatalyst surface }\end{array}$ & $\begin{array}{l}\text { Mrowetz } \\
\text { et al. } \\
\text { (2003) }\end{array}$ \\
\hline Methyl orange & $10 \mathrm{mg} / \mathrm{l}$ & $\begin{array}{l}(250-1250 \mathrm{mg} / \mathrm{l}) \mathrm{HOm} \text {-type sonicator } \\
(f=40 \mathrm{kHz}, i=50 \mathrm{~W}) \mathrm{pH} 3.0 \\
\text { (rutile/anatase) } \mathrm{TiO}_{2} \text { catalyst }\end{array}$ & $\begin{array}{l}\text { In companing the effectiveness of } \\
\text { rutile and anatase } \mathrm{TiO}_{2} \text { in a } \\
\text { sonocatalysis process, rutile } \\
\mathrm{TiO}_{2} \text { demonstrated better } \\
\text { degradation rate than anatase } \\
\mathrm{TiO}_{2} \text {. Furthermore, the catalytic } \\
\text { activity of reused rutile } \mathrm{TiO}_{2} \\
\text { catalyst was higher than that of } \\
\text { the new rutile } \mathrm{TiO}_{2}\end{array}$ & $\begin{array}{l}\text { Wang et al. } \\
\text { (2005) }\end{array}$ \\
\hline Naphthol blue black & $50 \mu \mathrm{M}$ & $\begin{array}{l}\text { (Degussa } \mathrm{P} 25) \mathrm{TiO}_{2}(1 \mathrm{~g} / \mathrm{L}), \\
\text { transducer-type sonicator } \\
(f=640 \mathrm{kHz}, i=240 \mathrm{~W})\end{array}$ & $\begin{array}{l}\text { Sonolysis was determined to } \\
\text { increase the degradation rate of } \\
\text { the targeted pollutant and }\end{array}$ & $\begin{array}{l}\text { Stock et al. } \\
\quad(2000)\end{array}$ \\
\hline
\end{tabular}




\begin{tabular}{|c|c|c|c|c|}
\hline $\begin{array}{l}\text { Contaminants } \\
\text { degraded }\end{array}$ & Concentration & Chemical oxidation scheme & Comments/discussion & References \\
\hline & & & $\begin{array}{l}\text { photocatalysis was instrumental } \\
\text { in promoting mineralization }\end{array}$ & \\
\hline Bisphenol A & $25 \mathrm{mg} / \mathrm{L}$ & $\begin{array}{l}\text { Ultrasonic intensity }(45-47 \mathrm{kHz}) \text {, } \\
i=500 \mathrm{~W} \text {, temperature }=25 \pm 5{ }^{\circ} \mathrm{C} \text {, } \\
\text { Fenton reagents (FeSO } 4.7 \mathrm{H}_{2} \mathrm{O} \text { and } \\
\mathrm{H}_{2} \mathrm{O}_{2} \text { ) }\end{array}$ & $\begin{array}{l}\text { There was an increase in the } \\
\text { degradation rate when ultrasonic } \\
\text { irradiation with Fenton process } \\
\text { were combined than the } \\
\text { individual process }\end{array}$ & $\begin{array}{l}\text { Ioan et al. } \\
\quad(2007)\end{array}$ \\
\hline $\begin{array}{l}\text { Monocrotophos } \\
\text { pesticide }\end{array}$ & $0.375 \mathrm{mg} / \mathrm{L}$ & $\begin{array}{l}\text { Volume of the solution, } 200 \mathrm{ml} ; \mathrm{pH}=4 \text {; } \\
\text { amount of addition, } 1 \mathrm{~g} / \mathrm{L} ; \text { time, } 2 \mathrm{~h}\end{array}$ & $\begin{array}{l}\text { With sonolysis alone, } 15 \% \\
\text { photocatalysis alone, } 80 \% \\
\text { sonophotocatalysis, } 92 \%\end{array}$ & $\begin{array}{l}\text { Kaur and } \\
\text { Agarwal } \\
\text { (2013) }\end{array}$ \\
\hline $\begin{array}{l}\text { 4-Chloro-2-nitro } \\
\text { phenol }\end{array}$ & $0.86 \mathrm{mM}$ & $\begin{array}{l}\text { Ultrasound intensity }(36 \mathrm{kZ}) \text {; volume } \\
\text { of the solution, } 200 \mathrm{ml} ; \mathrm{pH}=7 \text {; } \\
\text { amount of addition, } 1.5 \mathrm{~g} / \mathrm{L} \text { reaction } \\
\text { time }=120 \mathrm{~min}\end{array}$ & $\begin{array}{l}\text { Ultraviolet irradiation, } 9 \% \text {; } \\
\text { ultrasound irradiation, } 25 \% \text {; } \\
\text { ultrasound irradiation with } \\
\text { catalyst, } 46 \% \text {; ultrasound } \\
\text { irradiation with photocatalyst, } \\
61 \%\end{array}$ & $\begin{array}{l}\text { Anoop } \\
\text { et al. } \\
\text { (2013) }\end{array}$ \\
\hline
\end{tabular}

Adapted from Pankaj and Viraraghavan (2009) and Joseph et al. (2009)

The observed difference in the overall process efficiency may be ascribed to variation in the wastewater constituents. This is in line with the submission of Scott and Ollis (1995) that wastewater contaminants varies and may include recalcitrant, biodegradable, inhibitory, and intermediate dead end products. The removal efficiency of these pollutants depends on the applied treatment method. Application of chemical oxidation process for the removal of environmental toxicants is considered more expensive due to the formation of intermediate products. Aside from that, the toxicity level of the partially metabolized compounds remain an issue, as it has been observed that the intermediate products are more toxic than the parent compound and as such resistant to chemical decomposition. The conversion of these intermediate products into harmless inorganic compounds requires more energy, long reaction time, and use of expensive chemical oxidants such as ozone and others. These intermediates often compete with their parent molecules for available reactive species (Malik 2010). In order to safeguard cost and improve the performance of the chosen process, advanced oxidation technology such as electrohydraulic discharge process or sonolysis can be applied as a pretreatment step (Gaya and Abdullah 2008; Oller et al. 2011). This will enable easy removal and eventual conversion of persistent organic pollutants into biogenic compounds followed by biological oxidation process at a considerably lower cost (Oller et al. 2011). Alternatively, biological treatment can be applied as a pretreatment strategy to eliminate biodegradable fractions such as refractory and biogenic compounds from wastewater and subsequent application of plasma technology as a post-treatment process. This is often the case when dealing with real environmental wastewater. The former involves positioning of the AOP in series with the biological treatment. This kind of treatment process requires at least one AOP step and one biological treatment step (Oller et al. 2011). However, there is little information regarding combination of biological process and electrohydraulic discharge system in the literature. This area requires further studies. More so, Augugliaro et al. (2006) submitted that heterogeneous photocatalysis can be combined with other AOTs such as ultrasonic irradiation, ozonation, electrochemical treatment, photo-Fenton process, 
or with the existing conventional treatment technology (biological treatment, physical adsorption). The overall objective is to improve the process performance and efficiency. Whatever pathway chosen, the performance of the integrated process can be improved via different ways. Considering the extensive nature of wastewater treatment process, it is necessary to design a combined process that will be ecologically advantageous in terms of cost and performance. This means the integrated process must be technically and economically viable.

\subsection{Limitations of Advanced Oxidation Technology}

Although advanced oxidation technologies are relevant for the removal of a wide range of organic pollutants due to the high oxidative potential and efficiency, one of the shortcomings presently militating against the widely application or adoption especially in developing countries lay in its high operational cost such as high energy consumption and chemical oxidants. Moreover, considering the nature of the pollutants including their structural diversity and complexity, a singular advanced oxidation treatment may not completely degrade and mineralize the compounds. This is mostly due to interference by inorganic ions such as bicarbonate, sulphates, chlorides, nitrates, etc. These ions acts by scavenging the oxidizing power of the hydroxyl radicals and ultimately decrease the efficiency of the process. The matrix scavenging causes low oxidation efficiency of assimilable organic carbon formation given rise to the formation of unidentified transformation products. In order to avoid this problem, the interfering ions need to be removed-though will require more energy-thus causing additional costs and time. Advanced oxidation technologies cannot be used to treat large volume of wastewater unless pretreatment technique is applied.

\section{Conclusion and Future Studies}

This review has clearly and extensively demonstrated that combined advanced oxidation technology (such as electrohydraulic discharge with heterogeneous photocatalysis) or sonophotocatalysis process are capable of mineralizing toxic persistent and refractory prior ity pollutants than individual technique. This is due to the synergistic effect between the two individual treatment processes. The overall process efficiency of integrated process can be improved via coupling with biological treatment. These processes have been tested in the laboratory; therefore, there is a need to go beyond small-scale application. Future research should be directed towards developing new combined system that will be less energy intensive and more ecologically advantageous in terms of cost and performance. This means the integrated process must be technically and economically viable. This will involve an extensive collaborative research and multidisciplinary approach among institutions. This will not only be beneficial to water industries alone, it will also improve service delivery, raise the socioeconomic status, and guarantee environmental sustainability. Future research should be directed towards optimization of the plasma reactor including thorough explanation regarding the oxidative degradation mechanisms. There is need for thorough understanding regarding reaction of active species with the target pollutant. Not only that, efficient design and scaling up of the existing plasma reactor into full commercial utilization should be the focus of future research. Plasma technology is scale-up represent a new industrial wastewater treatment technique. However, the potential risk of priority pollutants in

\section{http://repository.uwc.ac.za}


water need to be thoroughly checked, aside from the strict adherence and enforcement of existing environmental legislations in order to protect the environment is desirable.

\section{Acknowledgments}

The authors acknowledge the Environmental and Nano Sciences Research Group, Department of Chemistry, University of the Western Cape, South Africa for the assistance. 


\section{References}

Abou-Ghazala, A., Katsuki, S., Schoenbach, K. H., Dobbs, F. C., \& Moreira, K. R. (2002). Bacterial decontamination of water by means of pulsed-corona discharges. IEEE Transactions on Plasma Science, 30, 1449.

Adewuyi, YG. (2001). Sonochemistry: Environmental Science and Engineering Applications. Industrial and Engineering Chemistry Research, 4O(22), 4681-4715

Adewuyi, Y. G. (2005). Sonochemistry in environmental remediation II: heterogeneous sonophotocatalytic oxidation processes for the treatment of pollutants in water. Environmental Science \& Technology, 39, 8557-8570.

Ahmed, S., Rasul, M. G., Martens, W. N., Brown, R. J., \& Hashib, M. A. (2010). Heterogeneous photocatalytic degradation of phenols in wastewater: a review on current status and developments. Desalination, 261(1-2), 3-18.

Akiyama, H. (2000). Streamer discharges in liquids and their applications. IEEE Trans. Dielectrics Electr. Insul, 7, 646.

Alrousan, D. M. A., Dunlop, P. S. M., McMurray, T. A., \& Anthony, B. J. (2009). Photocatalytic inactivation of $E$. coli in surface water using immobilised nanoparticle $\mathrm{TiO}_{2}$ films. Water Research, 43, 47-54.

Amar, L. Patil., Pankaj N. Patil \& Parag R. Gogate. (2014). Degradation of imidacloprid containing wastewaters using ultrasound based treatment strategies. Ultrasonics Sonochemistry, 21, 1778-1786.

Anandan, S., \& Ashokkumar, M. (2009). Sonochemical synthesis of $\mathrm{Au}-\mathrm{TiO}_{2}$ degradation of organic pollutants in aqueous environment. Ultrasonics Sonochemistry, 16, 316-320.

Anoop, V., Harmanpreet, K., \& Divya, D., (2013). Photocatalytic, sonolytic and sonophotocatalytic degradation of 4-chloro-2- nitro phenol. Archives of Environmental Protection, 39(2), 17-28.

Anju, S. G., Jyothi, K. P., Joseph, S., Suguna, Y., \& Yesodharan, E. P. (2012). Ultrasound assisted semiconductor mediated catalytic degradation of organic pollutants in water: comparative efficacy of $\mathrm{ZnO}, \mathrm{TiO}_{2}$ and $\mathrm{ZnO}^{-T i O}{ }_{2}$. Research Journal of Recent Sciences, 1, 191-201.

Autin, O., Hart, J., Jarvis, P., MacAdam, J., Parsons, S. A., \& Jefferson, B. (2012). Comparison of $\mathrm{UV} / \mathrm{H}_{2} \mathrm{O}_{2}$ and $\mathrm{UV} / \mathrm{TiO}_{2}$ for the degradation of metaldehyde: kinetics and the impact of background organics. Water Research, 46, 5655-5662.

Augugliaro, V., Litter, M., Palmisano, L., \& Soria, J. (2006). The combination of heterogeneous photocatalysis with chemical and physical operations: A tool for improving the photoprocess performance. Journal of Photochemistry and Photobiology C: Photochemistry Reviews, 7, 127-144.

Babkina, J., Stepanova, K., Krichevskaya, M., \& Preis, S. (2010). Aqueous photocatalytic oxidation of amoxicillin. Catalysis Today, 151, 39-45.

Bahmani, P., Maleki, A., Ghahramani, E., \& Rashidi, A. (2013). Decolorization of the dye reactive black 5 using Fenton oxi- dation. African Journal of Biotechnology, 12(26), $4115-4122$.

Bhanudas, N., Manoratne, C. H., Chandrashekhar, A., Iyer, A., Prasad, V. S.. Ghosh, N. N. (2012). Preparation of $\mathrm{TiO}_{2}$, Ag-doped $\mathrm{TiO}_{2}$ nanoparticle and $\mathrm{TiO}_{2}-\mathrm{SBA}-15$

\section{http://repository.uwc.ac.za}


nanocomposites using simple aqueous solution-based chemical meth- od and study of their photocatalytical activity. Journal of Experimental Nanoscience, 1-18.

Behnajady, M. A., Modirshahla, N., Shokri, M., \& Rad, B. (2008). Enhancement of photocatalytic activity of $\mathrm{TiO}_{2}$ nanoparticles by silver doping: photodeposition versus liquid impregnation methods. Global NEST Journal, 10, 1-7.

Bian. W., Ying. X., \& Shi, J. (2009). Enhanced degradation of p- chlorophenol in a novel pulsed high voltage discharge reactor. Journal of Hazardous Materials, 162, 906-912.

Bian, W., Song, X., Liu, D., Zhang, J., \& Chen, X. (2011). The intermediate products in the degradation of 4-chlorophenol by pulsed high voltage discharge in water. Journal of Hazardous Materials, 192(3), 1330-1339.

Bian, W., \& Lee, L. (2007). An electrohydraulic discharge system of salt-resistance for pchlorophenol degradation. Journal of Hazardous Material, 148, 178-184.

Bolong, N., Ismail, A. F., Salim, M. R., \& Matsuura, T. (2009). A review of the effects of emerging contaminants in wastewater and options for their removal. Desalination, 239, 229-246.

Bokhale, N. B., Bomble, S. D., Dalbhanjan, R. R., Mahale,D. D., Hinge, S. P., Banerjee, B. S., Mohod, A. V., \& Gogate, P. R. (2014).Sonocatalytic and sonophotocatalytic degradation of rhodamine 6G containing wastewaters. Ultrasonic Sonochemistry, 21, 17971804.

Bruggeman, P.J., \& Locke, B.R. (2013). Assessment of Potential Applications of Plasma with Liquid Water, in Low Temperature Plasma Technology: Methods and Applications, P. Chu, and X. Lu (Eds.), Taylor and Francis Group, Pp. 368- 369.

Capocelli, M., Joyce, E., Lancia, A., Mason, T. J., Musmarra, D., \& Prisciandaro, M. (2012). Sonochemical degradation of estradiols: incidence of ultrasonic frequency. Chemical Engineering Journal, 210(2012), 9-17.

Chanathaworn, J., Bunyakan, C., Wiyaratn, W., \& Chungsiriporn, J. (2012). Photocatalytic decolorization of basic dye by $\mathrm{TiO}_{2}$ nanoparticle in photoreactor. Songklanakarin Journal Sci. Technol, 34(2), 203-210.

Chandi, R., Ince, N. H., Gogate, P. R., \& Bremner, D. H. (2009). Phenol degradation using 20, 300 and $520 \mathrm{kHz}$ ultrasonic reactors with hydrogen peroxide, ozone and zero valent metals. Separation and Purification Technology, 67, 103-109. Chang, J. S., Urashima K, Uchida Y. (2002). Characteristics of pulsed arc electrohydraulic discharges and their application to water treatment. Res. Rep. Tokyo Denki Univ, 5O, 1

Chavadey, S., Kaitubolpaiboon, W., Rangsunvigit, P., Sreethawong, T., \& Mol, J. A. (2007). Combined multistage corona discharge and catalytic system for gaseous benzene removal. Catal. A.Chem, 263, 128-136.

Chefetz, B., Mualem, T., \& Ben-Ari, J. (2008). Sorption and mobility of pharmaceutical compounds in soil irrigated with reclaimed wastewater. Chemosphere, 73(8), 13351343.

Chen, J.-Q., Wang, D., Zhu, M.-X., \& Gao, C.-J. (2007). Photocatalytic degradation of dimethoate using nanosized $\mathrm{TiO}_{2}$ powder. Desalination, 207, 87-94.

Chen YC, Lee HM, Huang MH, Chen SH, Yan, JM. Yang MS. (2008). A discharge reactor with water-gas mixing for methyl orange removal. Paper presented at the sixth 
International Symposium on Non-thermal Plasma Technology for Pollution Control and Sustainable Energy Development (ISNTPT-6) held in Wanli, Taipei, Taiwan, May 12-16, 2008

Chong, M. N., Jin, B., Chow, C. W. K., \& Saint, C. (2010). Recent developments in photocatalytic water treatment technology: a review. Water Resources, 44, 2997-3027.

Chowdhury, P., \& Viraraghavan., T. (2009). Sonochemical degra- dation of chlorinated organic compounds, phenolic com- pounds and organic dyes - A review. Science of the Total Environment, 407, 2474-2492.

Dalrymple, O. K., Yeh, D. H., \& Trotz, M. A. (2007). Removing pharmaceuticals and endocrine-disrupting compounds from wastewater by photocatalysis. A review. Journal of Chemical Technology and Biotechnology, 82, 121-134.

Dang, T. H., Denat, A., Lesaint, O., \& Teissedre, G. (2009). Pulsed electrical discharges in water for removal of organic pollutants: a comparative study. The European Physical Journal Applied Physics, 47(2), 1-7.

Dobrin, D., Bradu, C., Magureanu, M., Mandachea, N. B., \& Parvulescu, V. I. (2013). Degradation of diclofenac in water using a pulsed corona discharge. Chemical Engineering Journal, 234, 389-396.

Dolat, N. Q., Kusiak-Nejman, E., Morawski, A. W., \& Puma Li, G. (2012). One step, hydrothermal synthesis of nitrogen, carbon co-doped titanium dioxide $(\mathrm{N}, \mathrm{C} \mathrm{TiO} 2)$ photocatalyst. Effects of alcohol degree and chain length as carbon dopant precursors on photocatalytic activity and catalyst deactivation. Applied Catalisis B: Environment, 115-116, 81-89.

Doosti, M. R., Kargar, R., \& Sayadi, M. H. (2012). Water treatment using ultrasonic assistance: a review. Proceedings of the International Academy of Ecology and Environmental Sciences, 2(2), 96-110.

Elmolla, E. S., \& Chaudhuri, M. (2010). Comparison of different advanced oxidation process for treatment of antibiotics aqueous solution. Desalination, 256, 43-47.

Emery, R. J., Papadaki, M., \& Mantzavinos, D. (2003). Sonochemical degradation of phenolic pollutants in aqueous solutions. Environmental Technology, 24, 1491-1500.

Entezari, M. H., Mostafai, M., \& Sarafraz-yazdi, A. (2006). A combination of ultrasound and a bio-catalyst: removal of 2-chlorophenol from aqueous solution. Ultrasonics Sonochemistry, 13, 37-41.

Esplugas, S., Bila, D. M., Krause, L. G. T., \& Dezotti, M. (2007). Ozonation and advanced oxidation technologies to remove endocrine disrupting chemicals (EDCs) and pharmaceutical and personal care products (PPCPs) in water effluents. Journal of Hazardous Materials, 149, 631-642.

Even-Ezra, Itay., Anat, Mizrahi., Daniel, Gerrity., Shane, Snyder., Andrew, Salveson., \& Ori Lahav. (2009). Application of a novel plasma-based advanced oxidation process for efficient and cost-effective destruction of refractory organics in tertiary effluents and contaminated groundwater. Desalination and Water Treatment, 11, 236-244.

Fawell, J., \& Ong, C. N., (2012). Emerging Contaminants and the Implications for drinking water. Water Resources Development, 28(2):247-263.

Fujishima, A., Rao, T. N., \& Tryk, D. A. (2000). Titanium dioxide photocatalysis. Journal of Photochemistry and Photobiology, C: Photochemistry Reviews, 1, 1-21. 
Gaya, U. I., \& Abdullah, A. H. (2008). Heterogeneous photocatalytic degradation of organic contaminants over titanium dioxide: a review of fundamentals, progress and problems. Journal of Photochemistry and Photobiology C, 9(1), 1-12.

Geng, M., \& Thagard, S. M. (2013). The effects of externally applied pressure on the ultrasonic degradation of rhodamine B. Ultrasonics Sonochemistry, 20, 618-625.

Gerrity, D., Stanford, B. D., Trenholm, R. A., \& Snyder, S. A. (2010). An evaluation of a pilotscale non-thermal plasma advanced oxidation process for trace organic compound degradation. Water Research, 44, 493-504.

Girginov, C., Stefchev, P., Vitanov, P., \& Dikov, H. (2012). Silver doped $\mathrm{TiO}_{2}$ photocatalyst for methyl orange degradation. Journal of Engineering Science and Technology Review, 5(4), 14-17.

Gogate, P. R., \& Pandit, A. B. (2004). A review of imperative technologies for wastewater. Chemosphere, $73,848-853$.

Grymonpré, D. R., Finney, W. C., \& Locke, B. R. (1999). Aqueous-phase pulsed streamer corona reactor using suspended activated carbon particles for phenol oxidation: model-data comparison. Chemical Engineering Science, 54, 3095-3105.

Gultekin, I., \& Ince, N. H. (2007). Synthetic endocrine disruptors in the environment and water remediation by advanced oxidation process. Journal of Environmental Management, 85, 816-832.

Guo, Z., \& Feng, R. (2009). Ultrasonic irradiation-induced degradation of low-concentration bisphenol A in aqueous solution. Journal of Hazardous Materials, 163, 855-860.

Guo, Z., Feng, R., Li, J., Zheng, Z., \& Zheng, Y. (2008). Degradation of 2,4-dinitrophenol by combining sonolysis and different additives. Journal of Hazardous Materials, 158(1), 164-169.

Hamdaoui, O., \& Naffrechoux, E. (2008). Sonochemical and photosonochemical degradation of 4-chlorophenol in aqueous media. Ultrasonics Sonochemistry, 15, 981987.

Hao, X. L., Zhou, M. H., \& Lei, L. C. (2007). Non-thermal plasma-induced photocatalytic degradation of 4-chlorophenol in water. Journal of Hazardous Materials, 141, 475-482.

Hao, X. L., Zhang, X. W., \& Lei, L. C. (2013).The Catalytic Effect of Metal Ions on the Degradation of 4-Chlorophenol Induced by an aqueous Pulsed Discharge Plasma. Plasma Science and Technology, 15(7), 677-684.

Hartmann, J., Bartels, P., Mau, U., Witter, M., Tumpling, W. V., 1930 Hofmann, J., \& Nietzschmann, E. (2008). Degradation of the 1931 drug diclofenac inwater by sonolysis in presence of catalysts. 1932 Chemosphere, 70, 453-461.

Homem, V., \& Santos, L. (2011). Degradation and removal methods of antibiotics from aqueous matrices - A review. Journal of Environmental Management, 92, 2304-2347.

Houtman, C. J. (2010). Emerging contaminants in surface waters and their relevance for the production of drinking water in Europe. Journal of Integrative Environmental Sciences, 7(4), 271-295.

Inoue, M., Masuda, Y., Okada, F., Sakurai, A., Takahashi, I., \& Sakakibara, M. (2008). Degradation of bisphenol A using sonochemical reactions. Water Research, 42, 13791386. 
Ioan, I., Wilson, S., Lundanes, E., \& Nechlai, A. (2007). Comparison of Fenton and sonoFenton bisphenol A degradation. Journal of Hazardous Materials, 142, 559-563.

Jamalluddin, N. A., \& Abdullah, A. Z. (2011). Reactive dye degradation by combined $\mathrm{Fe}(\mathrm{III}) / \mathrm{TiO}_{2}$ catalyst and ultrasonic irradiation: effect of $\mathrm{Fe}(\mathrm{III})$ loading and calcination temperature. Ultrasonics Sonochemistry, 18, 669-678.

Jiang, B., Qiu, J. Z. S., Mingbo, W., Yan, Q. Z. Z., \& Xue, Q. (2014). Review on electrical discharge plasma technology for wastewater remediation. Chemical Engineering Journal, 236, 348-368.

Johnson, D. C., Shamamian, V. A., Callahan, J. H., Denes, F. S., Manolache, S. O., \& Dandy, D. S. (2003). Treatment of methyl tert-butyl ether contaminated water using a dense medium plasma reactor: a mechanistic and kinetic investigation. Environmental Science \& Technology, 37(20), 4804- 4810.

Joseph, C. G., Puma, G. L., Bono, A., \& Krishnaiah, D. (2009). Sonophotocatalysis in advanced oxidation process: a short review. Ultrasonics Sonochemistry, 16, 583-589.

Joshi, R. P., \& Thagard, S. M. (2013). Streamer-like electrical discharges in water: part II. Environmental applications. Plasma Chemistry and Plasma Processing, 33, 17-49.

Kashyap, P. M ., \& Parag, R. G. (2011). Intensification of sonophotocatalytic degradation of p-nitrophenol at pilot scale capacity. Ultrasonics Sonochemistry, 18, 739-744.

Kasprzyk-Hordern, B., Dinsdale, R. M., \& Guwy, A. J. (2009). The removal of pharmaceuticals, personal cares products, endocrine disruptors and illicit drugs during wastewater treatment and its impact on the quality of receiving waters. Water Research, $43(2), 363-380$.

Kathryn, M., Onesios, A. E., Jim, T., Yu, A. E., \& Bouwer, E. J. (2009). Biodegradation and removal of pharmaceuticals and personal care products in treatment systems: a review. Biodegradation, 20, 441-466.

Katsumata, H., Okada, T., Kaneco, S., Suzuki, T., \& Ohta, K. (2011). Degradation of fenitrothion by ultrasound/ ferrioxalate/UV system. Ultrasonics Sonochemistry, 17, 200-206.

Kaur, A., \& Agarwal, V. (2013). Sonophotocatalytic degradation of monocrotophos pesticides using immersion well reactor. International Journal of Applied Engineering Research, 8(18), 2067-2074.

Khan, S., Khan, M. A., Hanjra, M. A., \& Mu, J. (2009). Pathways to reduce the environmental footprints of water and energy inputs in food production, food policy, treatment I: oxidation technologies at ambient conditions. Advances in Environmental Research, 34, 141-149.

Klavarioti, M., Mantzavinos, D., \& Kassinos, D. (2009). Removal of residual pharmaceuticals from aqueous systems by advanced oxidation processes. Environment International, $35,402-417$.

Kondo, Y., Yoshikawa, H., Awaga, K., Murayama, M., Mori, T., Sunada, K., Bandow, S., \& Iijima, S. (2008). Preparation, photocatalytic activities, and dye-sensitized solar-cell performance of submicron-scale $\mathrm{TiO}_{2}$ hollow spheres. Langmuir, 24, 547-550.

Krause, H., Schweiger, B., Schuhmacher, J., Scholl, S., \& Steinfeld, U. (2009). Degradation of the endocrine disrupting chemicals (EDCs) carbamazepine, clofibric acid, and iopromide by corona discharge over water. Chemosphere, 75, 163-168. 
Krause, H., Schweiger, B., Prinz, E., Kim, J., \& Steinfeld, U. (2011). Degradation of persistent pharmaceuticals in aqueous solutions by a positive dielectric barrier discharge treatment. Journal of Electrostatics, 69, 333-338.

Kritikos, D. E., Xekoukoulotakis, N. P., Psillakis, E., \& Mantzavinos, D. (2007). Photocatalytic degradation of reactive black 5 in aqueous solutions: effect of operating conditions and coupling with ultrasound. Water Research, 41, 2236-2246.

Kubo, M., Fukuda, H., Chua, X. J., \& Yonemoto, T. (2007). Kinetics of ultrasonic degradation of phenol in the presence of composite particles of titanium dioxide and activated carbon. Industrial and Engineering Chemistry Research, 46(3), 699-704.

Kutepov, A. M., Zakharov, A. G., \& Maksimov, A. I. (2000). Chemical processes initiated by a non-equilibrium plasma in solutions. Theoretical. Found. Chem. Eng, 34, 70.

Lang, P. S., Ching, W. K., Willberg, D. M., \& Hoffmann, M. R. (1998). Oxidative degradation of 2,4,6-trinitrotoluene by ozone in an electrohydraulic discharge reactor. Environmental Science \& Technology, 32, 3142-3148.

Lastre-Acosta, A. M., Cruz-Gonzalez, G., Nuevas-Paz, L., Jauregui-Haza, U. J., \& Teixeira, A. C. S. C. (2014). Ultrasonic degradation of sulfadiazine in aqueous solutions. Environmental Science Pollution Research. doi:10.1007/ s11356-014-27662.

Lei, L. C., Zhang, Y., Zhang, X. W., Du, Y. X., Dai, Q. Z., \& Han,

S. (2007). Degradation performance of 4-chlorophenol as a typical organic pollutant by a pulsed high voltage discharge system. Industrial and Engineering Chemistry Research, 46, 5469-5477.

Leitner Karpel Vel, N., Syoen, G., Romat, H., Urashima, K., \& Chang, J. S. (2005). Generation of active enti- ties by the pulsed arc electrohydraulic discharge system and application to removal of atrazine. Water Research, 39, 4705-4714.

Li, J., Zhou, Z., Wang, H., Li, G., \& Yan, W. (2007). Research on decoloration of dye wastewater by combination of pulsed discharge plasma and $\mathrm{TiO}_{2}$ nanoparticles. Desalination, 212,123-128.

Lian J., Guo J., Guo Y., Yang J., Kang, L. (2011). Degradation ofacid red B by the combined technology of ozonation and high- voltage pulsed discharge. 2011 International Conference on remote Sensing, Environment and Transportation Engineering (RSETE), Nanjing 24-26 June, 205-209

Lin, J. G., \& Ma, Y. S. (2000). Oxidation of 2-chlorophenol in water by ultrasound/Fenton method. Journal Environ. Eng- ASCE, 126, 130-137.

Liu, Y. N., Jin, D., Lu, X. P., \& Han, P. F. (2008). Study on degradation of dimethoate solution in ultrasonic airlift loop reactor. Ultrasonics Sonochemistry, 15, 755-760.

Locke, B. R., \& Thagard, S. M. (2012). Analysis and review of chemical reactions and transport processes in pulsed electrical discharge plasma formed directly in liquid water. Plasma Chemistry and Plasma Processing, 32, 875-917.

Locke, B. R., Sato, M., Sunka, P., Hoffmann, M. R., \& Chang, J. S. (2006). Electrohydraulic discharge and non-thermal plasma for water treatment. Industrial and Engineering Chemistry Research, 45(3), 882-905. 
Luiz, D. B., Genena, A. K., José, H. J., Moreira, R. F., \& Schröder, H. F. (2009). Tertiary treatment of slaughterhouse effluent: degradation kinetics applying UV radiation or $\mathrm{H}_{2} \mathrm{O}_{2} /$ UV. Water Science and Technology, 6o(7), 1869-1874.

Luiz, D. B., Genena, A. K., Virmond, E., José, H. J., Moreira, R. F., Gebhardt, W., \& Schröder, H. F. (2010). Identification of degradation products of erythromycin A arising from ozone and AOP treatment. Water Environment Research, 82, 797- 805.

Luiz, D. B., Silva, G. S., Vaz, E. A. C., José, H. J., \& Moreira, R. F. P. M. (2011). Evaluation of hybrid treatments to produce high quality reuse water. Water Science and Technology, 63(9), 46-51.

Lukeš, P., (2001). Water treatment by pulsed streamer corona. Institute of Chemical Technology, Prague and Institute of Plasma Physics, ASCR. Unpublished PhD thesis. Pp. 12

Lukes, P., Clupek, M., Sunka, P., Peterka, F., Sano, T., Negishi, N., Matsuzawa, S., \& Takeuchi, K. (2005). Degradation of Phenol by underwater pulsed corona discharge in combination with TiO2 photocatalysis. Res Chem. Intermediate, 31, 285-299.

Lukes, P., Clupek, M., \& Babicky, V. (2011). Discharge filamentary patterns produced by pulsed corona discharge at the interface between a water surface and air. IEEE Transactions on Plasma Science, 39(11), 2644-2645.

Ma, C. Y., Xu, J. Y., \& Liu, X. J. (2006). Decomposition of an azo dye in aqueous solution by combination of ultrasound and visible light. Ultrasonics, 22, 375-378.

MacGregor, S. J., Farish, O., Fouracre, R., Rowan, N. J., \& Anderson, J. G. (2000). Inactivation of pathogenic and spoil- age microorganisms in a test liquid using pulsed electric fields. IEEE Transactions on Plasma Science, 28, 144.

Machulek Jr., A., Oliveira, S. C., Osugi, M. E., Ferreira, V. S., Quina, F. H., Dantas, R. F., Oliveira, S. L., Casagrande, G. A., Anaissi, F. J., Silva, V. O., Cavalcante R. P., Gozzi, F., Ramos, D. D., da Rosa, A. P.P., Santos, A. P. F., de Castro, D. C., Nogueira, J.A. (2013). Application of different advanced oxidation processes for the degradation of organic pollutants. Chapter 6, Organic pollutants-monitoring, risk and treat- ment. InTech,. Croatia. pp 142.

Madhavan, J., Grieser, F., \& Ashokkumar, M. (2010a). Combined advanced oxidation processes for the synergistic degradation of ibuprofen in aqueous environments. Journal of Hazardous Materials, 178, 202-208.

Madhavan, J., Grieser, F., \& Ashokkumar, M. (2010b). Degradation of orange-G by advanced oxidation processes. Ultrasonics Sonochemistry, 17, 338-343.

Magureanu, M., Piroi, D., Mandache, N. B., David, V., Medvedovici, A., \& Parvulescu, V. I. (2010). Degradation of pharmaceutical compound pentoxifylline in water by nonthermal plasma treatment. Water Research, 44, 3445-3453.

Magureanu, C. B., Piroi, D., Nicolae, B. M., \& Parvulescu, V. (2013). Pulsed corona discharge for degradation of methylene blue in water. Plasma Chemistry and Plasma Processing, 33, 51-64.

MahamunI, N. N., \& Adewuyi, Y. G. (2010). Advanced oxidation processes (AOPs) involving ultrasound for waste water treatment: a review with emphasis on cost estimation. Ultrasonics Sonochemistry, 17, 990-1003. 
Mahvi, A. H. (2009). Application of ultrasonic technology for water and wastewater treatment. Iranian Journal of Public Health, 38(2), 1-17.

Malato, S., Fernandez-Ibanez, P., Maldonado, M. I., Blanco, J., \& Gernjak, W. (2009). Decontamination and disinfection of water by solar photocatalysis: recent overview and trends. Catalysis Today, 147, 1-59.

Maletz, S., Floehr, T., Beier, S., Klumper, C., Brouwer, A., Behnisch, P., Higley, E., Giesy, J. P., Hecker, M., Gebhardt, L. V., Pinnekamp, J., \& Hollert, H. (2013). In vitro characterization of the effectiveness of enhanced sewage treatment processes to eliminate endocrine activity of hospital effluents. Water Research, 47, 1545-1557.

Malik, M. A. (2010). Water purification by plasmas: which reactors are most energy efficient? Plasma Chemistry and Plasma Processing, 30, 21-31.

Marsili, L., Espie, S., \& Anderson, J. G. (2002). Plasma inactivation of food-related microorganisms in liquids. Rad. Phys. Chem, 65, 507.

Me'ndez-Arriaga, F., Santiago, E., \& Gime'nez, J. (2010). Degradation of the emerging contaminant ibuprofen in water by photo-Fenton. Water Research, 44, 589-595.

Mededovic, S., \& Locke, B. R. (2007). Side-chain degradation of atrazine by pulsed electrical discharge in water. Industrial and Engineering Chemistry Research, 46(9), 27022709.

Mededovic, S., Finney, W. C., \& Locke, B. R. (2007). Aqueous-phase mineralization of striazine using pulsed electrical dis- charge. IJPEST, 1(1), 82-90.

Miichi, T., Hayashi, N., Ihara, S., Satoh, S., \& Yamabe, C. (2002). Generation of radicals using discharge inside bubbles in water for water treatment. Ozone Science and Engineering, 24,47 .

Mrowetz, M., Pirola, C., \& Selli, E. (2003). Degradation of organic water pollutants through sonophotocatalysis in the presence of $\mathrm{TiO}_{2}$. Ultrasonics Sonochemistry, 10, 247-254.

Nainani, R., Pragati, T., \& Manohar, C. (2012). Synthesis of silver doped $\mathrm{TiO}_{2}$ nanoparticles for the improved photocatalytic degradation of methyl orange. Journal of Materials Science and Engineering, B, 2(1), 52-58.

Neppolian, B., Park, J. S., \& Choi, H. (2004). Effect of Fenton-like oxidation on enhanced oxidative degradation of parachlorobenzoic acid by ultrasonic irradiation. Ultrasonics Sonochemistry, 11, 273-279.

Okolongo, G. N., Buttner, U. B., Petrik, L., Perold, W. J. (2012a). Water treatment apparatus ref: P2269PCoo/MVS-new PCT international patent application no. PCT/IB2012/052290 in Stellenbosch University PCT application filed at the International Bureau of WIPO on 9 May 2012.

Okolongo, G. N., Buttner, U. B., Petrik, L., Perold, W. J. (2012b). Photo-catalyst and its preparation ref: P2270PCoo/MVS- new PCT international patent application no. PCT/IB2012/ 052291 in Stellenbosch University filed at the International Bureau of WIPO on 9 May 2012.

Okolongo, G. N., Buttner, U. B., Petrik, L., Perold, W. J. (2012c). South African provisional patent application title: "Water treatment apparatus" patent application no: 2011/03467; date of filing: 12 May 2011; Applicant(s): Stellenbosch University, Inventor(s): VS Ref No. P2269ZAoo/MVS; "RSA Patent Application No 2011/03467" GENEVA, Nov. 18-publication no. WO/2012/153271 was published on Nov. 15, 2012.

\section{http://repository.uwc.ac.za}


Olivier, L., Laurent, F., Michael, T., Diego, M., \& Stéphanie, O. (2013). Treatment of 4chlorobenzoic acid by plasma-based advanced oxidation processes. Chemical Engineering and Processing: Process Intensification. doi:10.1016/j.cep.2013. 06.008.

Oller, I., Malato, S., \& Sánchez-Pérez, J. A. (2011) Combination of Advanced Oxidation Processes and biological treatments for wastewater decontamination - A review. Science of the Total Environment, 409 (20), 4141-4166.

Palominos, R., Freer, J., Mondaca, M. A., \& Mansilla, H. D. (2008). Evidence for hole participation during photocatalytic oxidation of the antibiotic flumequine. Journal of Photochemistry and Photobiology A, 193, 139-145.

Pankaj, C., \& Viraraghavan, T. (2009). Sonochemical degradation of chlorinated organic compounds, phenolic compounds and organic dyes-a review. Science of the Total Environment, 407, 2474.

Patil, M. N., \& Pandit, A. B. (2007). Cavitation-a novel tech- nique for making stable nanosuspensions. Ultrasonics Sonochemistry, 14, 519-530.

Patil, A. L., Patil, P. N., \& Gogate, P. R. (2014). Degradation of imidacloprid containing wastewaters using ultrasound based treatment strategies. Ultrasonics Sonochemistry, $21,1778-1786$.

Qu, G., Liang, D., Qu, D., Huang, Y., Liu, T., Mao, H., Ji, P., \& Huang, D. (2013). Simultaneous removal of cadmium ions and phenol from water solution by pulsed corona discharge plasma combined with activated carbon. Chemical Engineering Journal, 228, 28-35.

Qusay Jaffer Rasheed, Kannaiyan Pandian., \& Karuppan Muthukumar. (2011). Treatment of petroleum refinery waste- water by ultrasound-dispersed nanoscale zero-valent iron particles. Ultrasonics Sonochemistry, 18, 1138-1142.

Rasheed, Q. J., Pandian, K., \& Muthukumar, K. (2011). Treatment of petroleum refinery wastewater by ultrasound-dispersed nanoscale zero-valent iron particles. Ultrasonics Sonochemistry, 18, 1138-1142.

Reddy, P. M. K., \& Subrahmanya, C. (2012). Green approach for wastewater treatmentdegradation and mineraliza- tion of aqueous organic pollutants by discharge plasma. Industrial and Engineering Chemistry Research, 51, 11097-11103.

Reddy, P. M. K., Rama Raju, B., Karuppiah, J., Linga Reddy, E., \& Subrahmanyam, C. H. (2013). Degradation and mineralization of methylene blue by dielectric barrier discharge nonthermal plasma reactor. Chemical Engineering Journal, 217, 41-47.

Ruma Lukes, P., Aoki, N., Spetlikova, E., Hosseini, S. H. R., Sakugawa, T., \& Akiyama, H. (2013). Effects of pulse frequency of input power on the physical and chemical properties of pulsed streamer discharge plasmas in water. Journal of Physics D: Applied Physics, 46, 125-202.

Sano, N., Yamane, Y., Hori, Y., Akatsuka, T., \& Tamon, H. (2011). Application of multiwalled carbon nanotubes in a wetted- wall corona-discharge reactor to enhance phenol decomposition in water. Industrial and Engineering Chemistry Research, 50, 9901-9909.

Sato, J. S., Clements, M., \& Davis, R. H. (1987). Preliminary investigation of prebreakdown phenomena and chemical re- actions using a pulsed high-voltage discharge in water. IEEE Transactions on Industry Applications, IA-23, 224-235. 
Sato, M., Ishida, N. M., Sugiarto, A. T., Oshima, T., \& Taniguchi, H. (2001). High efficiency sterilizer by high voltage pulse using concentrated field electrode system. IEEE Transactions on Industry Applications, 37, 1646.

Sato, M., Tokutake, T., Ohshima, T., \& Sugiarto, A. T. (2008). Aqueous phenol decomposition by pulsed discharges on the water surface. IEEE Transactions on Industry Applications, 44(5), 1397-1402.

Schoenbach, K. H., Joshi, R. P., Stark, R. H., Dobbs, F. C., \& Beebe, S. J. (2000). Bacterial decontamination of liquids with pulsed electric fields. IEEE Transactions on Dielectrics and Electrical Insulation, 7, 637.

Scott, J. P., \& Ollis, D. F. (1995). Integration of chemical and biological oxidation processes for water treatment: review and recommendations. Environmental Progress, 14(2), 88-103.

Seguraa, Y., Martíneza, F., Meleroa, J. A., Molinaa, R., Chandb, R., \& Bremner, D. H. (2012). Enhancement of the advanced Fenton process $\left(\mathrm{FeO} / \mathrm{H}_{2} \mathrm{O}_{2}\right)$ by ultrasound for the mineraliza- tion of phenol. Applied Catalysis B: Environmental, 113- 114, 100-106.

Sein, MM., Bin Nasir, Z., Telgheder, U, Schmidt, TC. (2012). Studies on a non-thermal pulsed corona plasma between two parallel-plate electrodes in water. Journal of Physics D: Applied Physics, 225203 (9pp)

Selli, E. (2002). Synergistic effects of sonolysis combined with photocatalysis in the degradation of an azo dye. Phys. Chem. Phys, 4, 6123-6128.

Shannon, M. A., Bohn, P. W., Elimelech, M., Georgiadis, J. G., Mariñas, B. J., \& Mayes, A. M. (2008). Science and technol- ogy for water purification in the coming decades. Nature, 452(20), 301-310.

Sandip, S., Ruparelia, JP, Patel, M. L. (2011) A general review on advanced oxidation processes for waste water treatment. Paper presented at the Institute of Technology, Nirma University, Ahmedabad, 382-481, 08-10

Shi, J., Bian, W., \& Yin, X. (2009). Organic contaminants removal by the technique of pulsed high-voltage discharge in water. Journal of Hazardous Materials, 171, 924-931.

Shimizu, N., Ogino, C., Dadjour, M. F., \& Murata, T. (2007). Sonocatalytic degradation of methylene blue with $\mathrm{TiO}_{2}$ pellets in water. Ultrasonics Sonochemistry, 14, 184-190.

Siddique, M., Khan, R., Khan, A. F., \& Farooq, R. (2014). Improved photocatalytic activity of $\mathrm{TiO}_{2}$ coupling ultrasound for reactive blue 19 degradation. Journal of the Chemical Society of Pakistan, 36(1), 37-43.

Stasinakis, A. S. (2008). Use of selected advanced oxidation processes (AOPS) for wastewater treatment-a mini review. Global NEST Journal, 1O(3), 376-385.

Stavarache, C., Yim, B., Vinatoru, M., \& Maeda, Y. (2002). Sonolysis of chlorobenzene in Fenton-type aqueous systems. Ultrasonics Sonochemistry, 9, 291-296.

Stock, N. L., Peller, J., Vinodgopal, K., \& Kamat, P. V. (2000). Combinative sonolysis and photocatalysis for textile dye degradation. Environmental Science and Technology, $34,1747$.

Sun, B., Sato, M., \& Clements, J. S. (2000). Oxidative processes occurring when pulsed high voltage discharges degrade phe- nol in aqueous solution. Environmental Science \& Technology, 34, 509-513. 
Sunka, P. (2001). Pulse electrical discharges in water and their applications. Physics of Plasmas, 8, 2587.

Swaminathan, M., Muruganandham, M., Sillanpaa, M. (2013). Advanced oxidation processes for wastewater treatment. International Journal of Photo Energy, Article ID 683682, 3 pages.

Tryba B, Piszcz M, Morawski AW. (2009). Photocatalytic activity of $\mathrm{TiO}_{2}-\mathrm{WO}_{3}$ composites. International Journal of Photoenergy, Article ID 297319, 7.

Tsai, W.-T., Mei-Kuei, L., Ting-Yi, S., \& Yuan-Ming, C. (2009). Photodegradation of bisphenolA in a batch $\mathrm{TiO}_{2}$ suspension reactor. Journal of Hazardous Materials, 168, 269-275.

Umar, U., Abdul Aziz, H. (2013). Photocatalytic degradation of organic pollutants in water: organic pollutants-monitoring, risk and treatment. Chapter 8. InTech Publisher, Croatia, pp. 197

Van Durme, J., Dewulf, J., Leys, C., \& Van Langenhove, H. (2008). Combining non-thermal plasma with heterogenous catalysis in waste gas treatment: a review. Applied Catalysis B: Environmental, 78, 324-333.

Wahyudiono, S. Machmudah and M. Goto (2013). Pulsed dis- charge plasma over a water surface induces decoloration of dyes. Journal of Physics: Conference Series 441: 012008

Wang, J., Guo, B., Zhang, X., Zhang, Z., Han, J., \& Wu, J. (2005). Sonocatalytic degradation of methyl orange in the presence of $\mathrm{TiO}_{2}$ catalysts and catalytic activity comparison of rutile and anatase. Ultrasonics Sonochemistry, 12(5), 331-337.

Wang, J., Sun, W., Zhang, Z., Li, X. Z. R., Ma, T., Zhang, P., \& Li, Y. (2007). Sonocatalytic degradation of methyl parathion in the presence of micron-sized and nano-sized rutile titanium dioxide catalysts and comparison of their sonocatalytic abilities. Journal of Molecular Catalysis A: Chemical, 272, 84-90.

Wang, H., Long, J. N. X., \& He, Y. (2008a). Sonophotocatalytic degradation of methyl orange by nano-sized $\mathrm{Ag} / \mathrm{TiO}_{2}$ parti- cles in aqueous solutions. Ultrasonics Sonochemistry, $15,386-392$.

Wang, H., Li, J., Quan, X., \& Yan, W. (2008b). Enhanced gener- ation of oxidative species and phenol degradation in a dis- charge plasma system coupled with $\mathrm{TiO}_{2}$ photocatalysis. Applied Catalysis B: Environmental, 83, 72-77.

Wang, H., Niu, J., Long, X., He, Y., \& He, Y. (2008c). Sonophotocatalytic degradation of methyl orange by nano-sized $\mathrm{Ag} / \mathrm{TiO}_{2}$ particles in aqueous solution. Ultrasonics Sonochemistry, 15(4), 386-392.

Wang, X., Jia, J., \& Wang, Y. (2011). Degradation of C.I. Reactive Red 2 through photocatalysis coupled with water jet cavitation. Journal of Hazardous Materials,185, 315-321.

Wang, H., Chu, J., Ou, H., Zhao, R., \& Han, J. (2009). Analysis of $\mathrm{TiO}_{2}$ photocatalysis in a pulsed discharge system for phenol degradation. Journal Electrostat, 67, 886-889.

Wang, X., Wang, J., Guo, P., Guo, W., \& Wang. C., (2009). Degradation of rhodamine B in aqueous solution by using swirling jet-induced cavitation combined with $\mathrm{H}_{2} \mathrm{O}_{2}$. Journal of Hazardous Materials, 169, 486-491. 
Weng, C.-H., Lin, Y.-T., Chang, C.-K., \& Liu, N. (2013). Decolourization of direct blue 15 by Fenton/ultrasonic pro- cess using a zero-valent iron aggregate catalyst. Ultrasonics Sonochemistry, 20(3), 970-977.

WHO (2012). Global water supply and sanitation assessment. Report, WHO/UNICEF Joint Monitoring Programme for Water Supply and Sanitation, World Health Organization and United Nations Children Fund.

Wu, Z. L., Ondruschka, B., \& Cravotto, G. (2008). Degradation of Phenol under Combined Irradiation of Microwaves and Ultrasound. Environmental Science Technology, 42, $8083-8087$.

Xu, X. W., Shi, H. X., \& Wang, D. H. (2005). Ozonation with ultrasound enhancement of pnitrophenol wastewater. Journal of Zhejiang University. Science, 6B(5), 319-323.

Yang, H., Ke, Z., Rongrong, S., Xianwei, L., Xiaodan, D., \& Yongmei, Y. (2006). Sol-gel synthesis of $\mathrm{TiO}_{2}$ nanoparticles and photocatalytic degradation of methyl orange in aqueous $\mathrm{TiO}_{2}$ suspensions. Journal of Alloys and Compounds, 413, 302-306.

Zastawny HZ, Romat H, Karpel vel Leitner N, Chang, JS. (2003). Pulsed arc discharges for water treatment and disinfection. In Electrostatics; IOP Publishers: Bristol, U.K., 137: 325

Zhang, L., \& Sun, B. (2006). Decoluration of the methylene blue by pulse discharge. APAWTGORT, 152-155.

Zhang, H., Duan, L., \& Zhang, D. (2006). Decolorization of methyl orange by ozonation in combination with ultrasonic irradiation. Journal of Hazardous Materials, B138, 53-59.

Zhang, Y., Sun, B., Deng, S., Wang, Y., Peng, H., Li, Y., \& Zhang, X. (2010). Methyl orange degradation by pulsed discharge in the presence of activated carbon fibers. Chemical Engineering Journal, 159, 47-52

Zhang, L., Sun, B., \& Zhu, X. (2009). Organic dye removal from aqueous solution by pulsed discharge on the pinhole. Journal of Electrostatics, 67, 62-66.

Zhang, J., Liu, D., Bian, W., \& Chen, X. (2012). Degradation of 2, 4-dichorophenol by pulsed high voltage discharge in water. Desalination, 304, 49-56.

Zhang, Y., Lu, J., Wang, X., Xin, Q., Cong, Y., Wang, Q., \& Li, C. (2013a). Phenol degradation by $\mathrm{TiO}_{2}$ photocatalysts com- bined with different pulsed discharge systems. Journal of Colloid and Interface Science, 409, 104-111.

Zhang, Y., Xin, Q., Cong, Y., Wang, Q., \& Jiang, B., (2013b). Application of $\mathrm{TiO}_{2}$ nanotubes with pulsed plasma for phenol degradation. Chemical Engineering Journal, 215-216, 261-268.

Zhang, Y., Xiong, X.Y., Han, Y., \& Zhou, W. (2011). Comparison of catalysis of different activated carbon in pulsed discharge reactor. Procedia Environmental Sciences, 11, 668-673.

Zhang, Y., Xiong, X., Han, Y., Yuan, H., Deng, S., Xiao, H., Wu, X., \& Shen, F. (2010). Application of titanium dioxide- loaded activated carbon fiber in a pulsed discharge reactor for degradation of methyl orange. Chemical Engineering Journal, 162, 1045-1049.

Zhang, Y., Zhang, R., Ma, W., Zhang, X., Wang, L., \& Guan, Z. (2013). Purification of water by bipolar pulsed discharge plasma combined with $\mathrm{TiO}_{2}$ catalysis. Journal of Physics: Conference Series 418, 012125 
Zhou, T., Lu, X., Wang, J., Wong, F. S., \& Li, S. (2009). Rapid decolorization and mineralization of simulated textile wastewater in a heterogeneous Fenton like system with/without external energy. Journal Hazard. Mat, 165, 193-199.

Zhu, J., Yang, D., Geng, J., Chen, D., \& Jiang, Z. (2008). Synthesis and characterization of bamboo-like $\mathrm{CdS} / \mathrm{TiO}_{2}$ nanotubes composites with enhanced visible-light photocatalytic activity. Journal Nanoparticle Research, 10, 729.

Zhu, L., Wang, Y., Ren, Z., Liu, G., \& Kang, K. (2013). The degradation of organic pollutants by bubble discharge in water. Plasma Science and Technology, 15(10), 1053-1058. 